University of Nebraska - Lincoln

DigitalCommons@University of Nebraska - Lincoln

2013

\title{
High Spatial Resolution Mapping of Elevated Atmospheric Carbon Dioxide Using Airborne Imaging Spectroscopy: Radiative Transfer Modeling and Power Plant Plume Detection
}

\author{
Philip E. Dennison \\ University of Utah \\ Andrew K. Thorpe \\ University of California-Santa Barbara \\ Eric R. Pardyjak \\ University of Utah \\ Dar A. Roberts \\ University of California-Santa Barbara, dar@geog.ucsb.edu \\ Yi Qi \\ University of Nebraska-Lincoln, yqi7@unl.edu
}

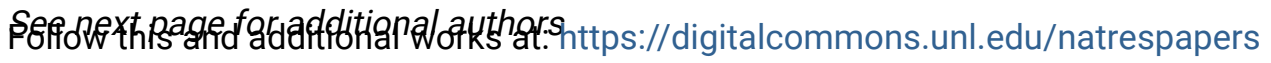

Part of the Natural Resources and Conservation Commons, Natural Resources Management and Policy Commons, and the Other Environmental Sciences Commons

Dennison, Philip E.; Thorpe, Andrew K.; Pardyjak, Eric R.; Roberts, Dar A.; Qi, Yi; Green, Robert O.; Bradley, Eliza S.; and Funk, Christopher C., "High Spatial Resolution Mapping of Elevated Atmospheric Carbon Dioxide Using Airborne Imaging Spectroscopy: Radiative Transfer Modeling and Power Plant Plume Detection" (2013). Papers in Natural Resources. 1004.

https://digitalcommons.unl.edu/natrespapers/1004

This Article is brought to you for free and open access by the Natural Resources, School of at DigitalCommons@University of Nebraska - Lincoln. It has been accepted for inclusion in Papers in Natural Resources by an authorized administrator of DigitalCommons@University of Nebraska - Lincoln. 


\section{Authors}

Philip E. Dennison, Andrew K. Thorpe, Eric R. Pardyjak, Dar A. Roberts, Yi Qi, Robert O. Green, Eliza S.

Bradley, and Christopher C. Funk 


\title{
High spatial resolution mapping of elevated atmospheric carbon dioxide using airborne imaging spectroscopy: Radiative transfer modeling and power plant plume detection
}

\author{
Philip E. Dennison ${ }^{\mathrm{a}, *}$, Andrew K. Thorpe ${ }^{\mathrm{b}}$, Eric R. Pardyjak ${ }^{\mathrm{c}}$, Dar A. Roberts ${ }^{\mathrm{b}}$, Yi Qi ${ }^{\mathrm{a}}$, Robert O. Green ${ }^{\mathrm{d}}$, \\ Eliza S. Bradley ${ }^{\mathrm{b}}$, Christopher C. Funk ${ }^{\mathrm{b}}$ \\ a Department of Geography, University of Utah, 260 S Central Campus Dr., Room 270, Salt Lake City, UT 84112, USA \\ ${ }^{\mathrm{b}}$ Department of Geography, University of California Santa Barbara, Santa Barbara, CA 93106, USA \\ c Department of Mechanical Engineering, University of Utah, Salt Lake City, UT 84112, USA \\ d Jet Propulsion Laboratory, California Institute of Technology, Pasadena, CA 91109, USA
}

\section{A R T I C L E I N F O}

\section{Article history:}

Received 28 October 2012

Received in revised form 25 June 2013

Accepted 1 August 2013

Available online $\mathrm{xxx}$

\section{Keywords:}

AVIRIS C

AVIRIS NG

MODTRAN

Noise equivalent delta radiance

Hyperspectral data

Imaging spectroscopy

$\mathrm{CO}_{2}$ emissions

Fossil fuel power plant

\begin{abstract}
A B S T R A C T
Carbon dioxide is emitted from the combustion of fossil fuels and is an important contributor to anthropogenic climate change. Multiple current and planned satellite missions are designed to quantify atmospheric carbon dioxide concentrations on a global scale, but most of these sensors do not have the spatial resolution necessary to resolve point sources such as fossil fuel power plants. Airborne imaging spectrometer data, such as those from the Airborne Visible InfraRed Imaging Spectrometer (AVIRIS), can have multiple, contiguous bands covering shortwave infrared (SWIR) absorption features produced by carbon dioxide. Therefore, high spatial resolution data from AVIRIS-like sensors may offer a means for detecting plumes and retrieving carbon dioxide concentrations for point source emissions. The objectives of this study include modeling minimum carbon dioxide anomalies detectable in AVIRIS data under different conditions and applying a Cluster-Tuned Matched Filter for detection of carbon dioxide plumes in simulated data and in AVIRIS images acquired over power plants. Radiative transfer simulations were used to model the residual radiance produced by increased absorption by carbon dioxide as concentration was elevated above background levels within a 0-500 m layer. Carbon dioxide anomalies, surface reflectance, water vapor concentration, solar zenith angle, sensor height, and aerosol scattering were varied in simulation sets and the resulting residual radiance spectra were compared against noise equivalent delta radiance (NEdL) for the "classic" and "next generation" AVIRIS instruments. Sensitivity to carbon dioxide anomalies improved with increased surface reflectance and declined with increased water vapor concentration, solar zenith angle, sensor height, and aerosol scattering. Zero to $500 \mathrm{~m}$ concentration anomalies as low as 100 parts per milion by volume (ppm) for AVIRIS C and $25 \mathrm{ppm}$ for AVIRIS NG produced residual radiance values that exceeded SWIR NEdL. Carbon dioxide concentrations modeled for a generic power plant emissions scenario using a plume dispersion model were combined with randomly-generated reflectance spectra to create simulated images with varying surface reflectance and NEdL. For these simulated images, true positive and false positive detection rates improved as background reflectance increased and as NEdL decreased. Apparent plumes were detected in all four AVIRIS C images acquired over power plants, although the characteristics of the plumes varied according to solar-plume-sensor geometry. Improvements in modeling may allow retrieval of plume concentration, providing a valuable means for quantifying point source emissions and a basis for comparison with column concentrations retrieved from in situ measurements and coarse resolution satellite data.
\end{abstract}

(c) 2013 Elsevier Inc. All rights reserved.

\section{Introduction}

Greenhouse gases affect Earth's energy balance by absorbing outgoing longwave radiation. Anthropogenic increases in the atmospheric concentration of multiple greenhouse gases, including carbon dioxide $\left(\mathrm{CO}_{2}\right)$, methane $\left(\mathrm{CH}_{4}\right)$, nitrous oxide $\left(\mathrm{N}_{2} \mathrm{O}\right)$, and halocarbons, have caused

\footnotetext{
* Corresponding author. Tel.: +1 8015851805.

E-mail address: dennison@geog.utah.edu (P.E. Dennison).
}

positive radiative forcing resulting in increased global temperature (Forster et al., 2007). Of the long-lived greenhouse gases, carbon dioxide has contributed the most radiative forcing since the start of the industrial era. Pre-industrial atmospheric concentrations are estimated between 275 and 285 parts per milion by volume (ppm) (Forster et al., 2007). Cumulative emissions from fossil fuel combustion and cement production have exceeded 350 billion tons of carbon (Boden, Marland, \& Andres, 2011), resulting in a global average carbon dioxide concentration surpassing 390 ppm in 2012 (NOAA, 2012). 
Increasing population and demand for electricity has resulted in increased global energy consumption, with the global annual primary energy supply nearly doubling between $1973\left(2.56 \times 10^{20} \mathrm{~J}\right)$ and $2009\left(5.09 \times 10^{20} \mathrm{~J}\right)($ IEA, 2011). The dominant source of electricity generation is power plant combustion of fossil fuels, resulting in point source emission that comprises a significant share of global anthropogenic carbon dioxide emissions. Within the United States, $40.6 \%$ of $\mathrm{CO}_{2}$ emissions are attributed to stationary sources that generate electricity by combusting fossil fuels (EPA, 2012). Emission estimates from power plants can have large uncertainties; for example, Ackerman and Sundquist (2008) found a 16.9\% average absolute difference for emission estimates from the U.S. Department of Energy's Energy Information Administration (EIA) and the U.S. Environmental Protection Agency's eGRID database. In the U.S., uncertainty in fossil fuel carbon dioxide emissions was estimated to be between -1 and 6\% (EPA, 2011). For the EU-25 nations emission uncertainty was 7\% when comparing four inventory methods (Ciais et al., 2010), and between 15 and 20\% for China when including both fossil fuel consumption and cement production (Gregg, Andres, \& Marland, 2008).

Given these uncertainties, there is increased interest in developing methods of quantifying anthropogenic carbon dioxide emissions using remote sensing. Past and ongoing satellite missions have provided the ability to monitor global carbon dioxide concentrations at coarse spatial resolutions, including the Atmospheric Sounding Interferometer (IASI; Crevoisier et al., 2009), the Atmospheric Infrared Sounder (AIRS; Jiang, Chahine, Olsen, Chen, \& Yung, 2010), the Tropospheric Emission Spectrometer (TES; Kulawik et al., 2010), the Scanning Imaging Absorption Spectrometer for Atmospheric Chartography (SCIAMACHY; Schneising et al., 2008), and the Greenhouse Gas Observing Satellite (GOSAT; Saitoh, Imasu, Ota, \& Niwa, 2009). In addition to detecting temporal and spatial variability in carbon dioxide concentrations, data like those provided by SCIAMACHY and GOSAT have great potential for estimating surface fluxes by inverse modeling of satellite observations (Chevallier et al., 2009; Schneising et al., 2012). Scheduled for launch in 2014, the Orbiting Carbon Observatory (OCO)-2 is equipped with a near infrared (NIR)/SWIR spectrometer that should provide a 1 ppm column concentration accuracy and km-scale spatial resolution needed for constraining regional sources and sinks (Crisp et al., 2004). Further, space-based detection of carbon dioxide emissions from power plants appears feasible using the proposed Carbon Monitoring Satellite (CarbonSat; Velazco et al., 2011).

Airborne sensors offer the potential to better constrain local emissions and improve greenhouse gas budgets (NRC, 2010). Recently developed airborne sensors have great potential for measuring carbon dioxide emissions at local and regional scales while complementing global monitoring efforts at coarser resolutions. For example, the non-imaging SWIR spectrometer MAMAP (Methane Airborne MAPper) has been used to measure a carbon dioxide plume emitted from a coal-fired power plant (Bovensmann et al., 2010). As part of the Carbon in Arctic Reservoirs Vulnerability Experiment (CARVE), a nadir-viewing Fourier transform spectrometer (FTS) is being used to measure total atmospheric columns of carbon dioxide in Alaskan terrestrial ecosystems (Miller \& Dinardo, 2012). However, these sensors provide atmospheric column concentrations for a small footprint; MAMAP is non-imaging and has a ground sample distance of approximately $33 \mathrm{~m}$ for a $1 \mathrm{~km}$ flight height (Gerilowski et al., 2011), while the FTS telescope for the CARVE mission has a $10^{\circ}$ field of view with a spatial resolution approximately $100 \times 1000$ m (Miller \& Dinardo, 2012).

The finer spatial resolution Airborne Visible InfraRed Imaging Spectrometer (AVIRIS) measures reflected solar radiance across 224 contiguous spectral bands between 350 and $2500 \mathrm{~nm}$ with a $10 \mathrm{~nm}$ spectral sampling (Green, Eastwood, \& Williams, 1998). For the "classic" AVIRIS instrument (AVIRIS C) spatial resolution typically ranges between 3 and $20 \mathrm{~m}$ depending on platform altitude, while the "next generation" AVIRIS instrument (AVIRIS NG) is capable of spatial resolutions as fine as $1 \mathrm{~m}$ with an improved spectral sampling of $5 \mathrm{~nm}$. The objectives of this study are to establish minimum carbon dioxide anomalies as thresholds for plume detection, and to demonstrate carbon dioxide plume detection in simulated images and in AVIRIS $C$ data acquired over power plants. Using radiative transfer modeling, we compare residual radiance caused by increased carbon dioxide absorption to noise equivalent delta radiance for AVIRIS C and AVIRIS NG. Simulated images and AVIRIS C images acquired over four U.S. power plants are used to demonstrate carbon dioxide plume detection based on a Cluster-Tuned Matched Filter (CTMF) approach.

\section{Background}

In addition to strong vibrational absorptions in the mid infrared and longwave (thermal) infrared, carbon dioxide has distinct vibrationalrotational absorptions in the SWIR. Fig. 1 shows modeled atmospheric transmittance for the three primary greenhouse gases: carbon dioxide, methane, and water vapor. These transmittance spectra were generated using the MODTRAN radiative transfer model (Berk, Bernstein, \& Robertson, 1989) and convolved to the $10 \mathrm{~nm}$ spectral sampling of AVIRIS C. The strongest carbon dioxide absorptions peak at approximate wavelengths of 1960, 2010, and $2060 \mathrm{~nm}$. At shorter wavelengths in this range, carbon dioxide absorption features overlap with strong water vapor absorption (Fig. 1). Weaker carbon dioxide absorption features present at 1570 and $1600 \mathrm{~nm}$ are free of strong water vapor absorption, but the absorption feature at $1430 \mathrm{~nm}$ is completely within a strong water vapor absorption band.

Imaging spectrometer data that include carbon dioxide SWIR absorption bands have potential for mapping spatial variation in atmospheric carbon dioxide concentration. Absorption of reflected solar radiance occurs for both direct and scattered radiance, complicating measurement of the carbon dioxide absorption signal. Solar zenith angle, view zenith angle, sensor height, and surface elevation determine the length of the direct path. These factors, along with scattering and absorption by water vapor and aerosols, influence carbon dioxide absorption of scattered radiance. While the length of the direct path is usually known, aerosol and water vapor effects are often unknown and must be measured. Atmospheric pressure and temperature also impact carbon dioxide absorption through broadening of absorption lines at higher pressures and temperatures. All radiance measured by a sensor is normally assumed to be solar radiance, but emitted radiance can significantly reduce apparent carbon dioxide absorption by greatly reducing path length (Dennison, 2006). Reduction in carbon dioxide absorption due to emitted radiance provides a means for fire detection using imaging spectrometer data (Dennison, 2006; Dennison \& Roberts, 2009; Matheson \& Dennison, 2012).

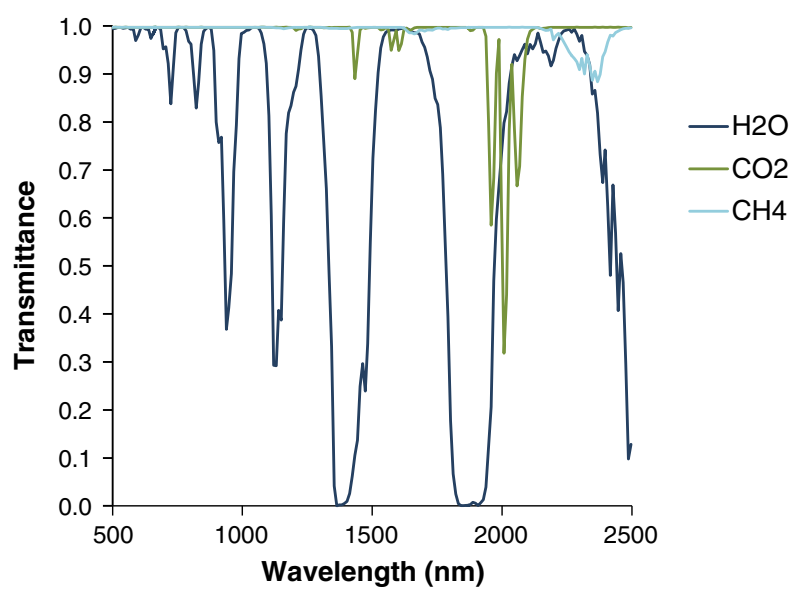

Fig. 1. Atmospheric transmittance for the three primary greenhouse gases, based on a MODTRAN simulation convolved to the 2011 AVIRIS C sensor response function. 
Parameters such as solar and view zenith angles, sensor and surface height, aerosol scattering characteristics, and atmospheric water vapor concentration can be used as inputs for radiative transfer modeling of reflected solar radiance. Concentration of carbon dioxide in the modeled atmospheric column can be altered to determine the effects of concentration on reflected radiance, and radiance or index values can be used to retrieve trace gas concentration using model inversion (Roberts et al., 2010). Previous efforts have used radiative transfer modeling to demonstrate carbon dioxide concentration retrieval from AVIRIS C data. Marion, Michel, and Faye (2004) estimated carbon dioxide concentrations from AVIRIS C data using the Joint Reflectance and Gas Estimator (JRGE), a two-step algorithm that first calculates surface reflectance and then carbon dioxide column concentrations. Concentrations estimated from multi-pixel areas within an AVIRIS C image obtained during the 1994 Quinault prescribed fire in Washington State were in good agreement with in situ carbon dioxide measurements (Marion et al., 2004). In a subsequent study using the same AVIRIS C image, the accuracy of carbon dioxide concentrations was improved by estimating aerosol properties using a look up table (LUT) inversion approach prior to running the JRGE algorithm (Deschamps, Marion, Briottet, Foucher, \& Lavigne, 2011). Using a Continuum Interpolated Band Ratio (CIBR) based on a carbon dioxide absorption maximum at $2011 \mathrm{~nm}$ and accounting for aerosol and water vapor content, Spinetti, Carrere, Buongiorno, Sutton, and Elias (2008) calculated carbon dioxide concentrations ranging from 40 to $350 \mathrm{ppm}$ above background and estimated an integrated flux rate in good agreement with in situ measurements.

Imaging spectrometer data have been used to quantify spatial variation in trace gas absorption, including water vapor, carbon dioxide, and methane. Gao and Goetz (1990) used water vapor absorption bands at 940 and $1140 \mathrm{~nm}$ to retrieve column water vapor amounts and generate maps for entire AVIRIS C scenes. Green, Conel, and Roberts (1993) developed a radiative transfer-based inversion to calculate column water vapor from AVIRIS C data, and Roberts, Green, and Adams (1997) used this method to observe a strong linear, inverse relationship between elevation and column water vapor as well as seasonal variations across multiple scenes. Ben-Dor and Kruse (1996) used Geophysical Environmental Research (GER) 63 spectrometer data to show that carbon dioxide and water vapor absorption vary with surface elevation due to changes in path length. Ogunjemiyo et al. (2002) demonstrated that AVIRIS C data can be used to detect elevated water vapor concentrations resulting from evapotranspiration under favorable boundary layer conditions.

AVIRIS $C$ has a signal-to-noise ratio that is favorable to mapping increased methane concentrations (Leifer, Roberts, Margolis, \& Kinnaman, 2006), and Roberts et al. (2010) estimated methane concentrations over the Coal Oil Point (COP) seep field in the Santa Barbara Channel, California by calculating spectral residuals and a methane index. Bradley, Leifer, Roberts, Dennison, and Washburn (2011) developed a band ratio technique using methane absorption band (2298 nm) and carbon dioxide absorption band (2058 nm) radiance. For solar-view geometries providing sun glint, they were able to clearly map a methane plume at the COP site. For spectrally and spatially heterogeneous terrestrial surfaces, Thorpe et al. (2013) mapped a number of methane plumes from natural seeps and fugitive emissions using a Cluster-Tuned Matched Filter approach (Funk, Theiler, Roberts, \& Borel, 2001) applied to AVIRIS C scenes from the Los Angeles Basin. Based on this previous work with methane seeps, point sources offer the strongest potential for detection of carbon dioxide plumes using AVIRIS data.

\section{Methods}

\subsection{Radiative transfer modeling}

MODTRAN 5.3 (Berk et al., 2005) was used to simulate the effects of increased carbon dioxide concentration on reflected solar radiance. Six different sets of simulations that varied atmospheric and geometric characteristics were created (Table 1). Within the modeled atmospheres, background carbon dioxide concentration was set to $390 \mathrm{ppm}$ across the entire atmospheric profile. All simulation sets also created an atmospheric layer from sea level to an altitude of $500 \mathrm{~m}$, within which the carbon dioxide concentration could be increased to simulate the presence of a carbon dioxide plume. Concentration within this layer was varied from $25 \mathrm{ppm}$ above background to $1600 \mathrm{ppm}$ above background. For each increment in each simulation set, the carbon dioxide anomaly within the 0-500 m layer was doubled (Table 1). Equivalent integrated column anomalies for each $500 \mathrm{~m}$ layer anomaly are shown in Table 2. Two-way transmittance was assumed for the 0-500 m layer, so modeled solar radiance passed through the layer in both the downwelling and upwelling directions.

Values used for surface reflectance, atmospheric water vapor concentration, solar zenith angle, and sensor height were based on the ranges of values found in previously studied AVIRIS C images (e.g. Dennison et al., 2003; Matheson \& Dennison, 2012). The baseline simulation set used a $15 \%$ background reflectance, a $25 \mathrm{~mm}$ atmospheric water vapor concentration, a $35^{\circ}$ solar zenith angle, and a $10 \mathrm{~km}$ sensor height. Baseline reflectance, water vapor, and solar zenith angle values were representative of averages over previously studied AVIRIS C images, and the $10 \mathrm{~km}$ sensor height was a compromise between extremes in the range of altitudes AVIRIS C data are collected from (3-20 km). For the reflectance simulation set, reflectance was varied from a minimum of $2.5 \%$ to a maximum of $50 \%$. All other parameters used values from the baseline simulation set (Table 1 ). The water vapor simulation set varied the depth of water vapor from a minimum of $10 \mathrm{~mm}$ to a maximum of $40 \mathrm{~mm}$. The solar zenith simulation set varied solar zenith angle from $0^{\circ}$ to $70^{\circ}$. The sensor height simulation set varied the altitude of the sensor from $500 \mathrm{~m}$ above sea level to $100 \mathrm{~km}$ above sea level. $100 \mathrm{~km}$

Table 1

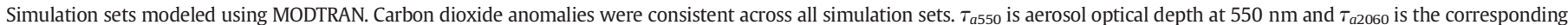
aerosol optical depth at $2060 \mathrm{~nm}$.

\begin{tabular}{|c|c|c|c|c|c|c|}
\hline Simulation set & $\begin{array}{l}\mathrm{CO}_{2} \text { anomaly } \\
\text { (ppm above background) }\end{array}$ & Reflectance & $\begin{array}{l}\text { Water vapor } \\
(\mathrm{mm})\end{array}$ & $\begin{array}{l}\text { Solar zenith angle } \\
\left({ }^{\circ}\right)\end{array}$ & $\begin{array}{l}\text { Sensor height } \\
(\mathrm{km})\end{array}$ & $\begin{array}{l}\tau_{a 550} \\
\tau_{a 2060}\end{array}$ \\
\hline Baseline & $0,25,50,100,200,400,800,1600$ & 0.15 & 25 & 35 & 10 & $\begin{array}{l}0.325 \\
0.039\end{array}$ \\
\hline Reflectance & & $0.025-0.50$ & 25 & 35 & 10 & $\begin{array}{l}0.325 \\
0.039\end{array}$ \\
\hline Water vapor & & 0.15 & $10-40$ & 35 & 10 & $\begin{array}{l}0.325 \\
0.039\end{array}$ \\
\hline Zenith angle & & 0.15 & 25 & $0-70$ & 10 & $\begin{array}{l}0.325 \\
0.039\end{array}$ \\
\hline Height & & 0.15 & 25 & 35 & $0.5-100$ & $\begin{array}{l}0.325 \\
0.039\end{array}$ \\
\hline Aerosol & & 0.15 & 25 & 35 & 10 & $\begin{array}{l}0.1-3.0 \\
0.01-0.43\end{array}$ \\
\hline
\end{tabular}


Table 2

Equivalent integrated column anomalies for each 0-500 m carbon dioxide anomaly used for MODTRAN modeling.

\begin{tabular}{lc}
\hline $0-500 \mathrm{~m}$ anomaly $(\mathrm{ppm})$ & Column anomaly $(\mathrm{ppm})$ \\
\hline 25 & 1.4 \\
50 & 2.8 \\
100 & 5.6 \\
200 & 11.3 \\
400 & 22.5 \\
800 & 45.1 \\
1600 & 90.2 \\
\hline
\end{tabular}

is effectively the height of a satellite platform, since the highest layer modeled in MODTRAN ended at an altitude of $100 \mathrm{~km}$.

All simulations used a mid-latitude summer atmospheric profile. The default rural boundary layer aerosol profile (for layers up to $2 \mathrm{~km}$ altitude) and tropospheric aerosol profile (for layers above $2 \mathrm{~km}$ and up to $10 \mathrm{~km}$ altitude) in MODTRAN were used to model scattering and absorption by aerosols. MODTRAN also allows selection of urban or maritime boundary layer aerosol characteristics (Shettle \& Fenn, 1979); rural boundary layer aerosol characteristics were used for this study due to the rural location of most power plants in the United States. Aerosol optical depth at $550 \mathrm{~nm}\left(\tau_{a 550}\right)$ is used by MODTRAN to scale aerosol extinction across all wavelengths. $\tau_{a 550}$ for the first five simulation sets was set to a value of 0.325 , which corresponds to an aerosol optical depth at $2060 \mathrm{~nm}\left(\tau_{a 2060}\right)$ of 0.039 . The aerosol simulation set varied $\tau_{a 550}$ from 0.1 to 3.0, equivalent to a range in $\tau_{a 2060}$ of 0.01 to 0.43 (Table 1 ).

The at-sensor reflected solar radiance modeled by each MODTRAN simulation was convolved using the sensor response function of AVIRIS C for 2011, producing radiance spectra with 224 bands and an approximate $10 \mathrm{~nm}$ full width half maximum. For each spectrum within a simulation set, a residual radiance was calculated by subtracting the spectrum from a spectrum with no elevated carbon dioxide concentration. Within the spectral region with the highest residuals (2000$2090 \mathrm{~nm}$ ), bands centered closest to $2000 \mathrm{~nm}$ (moderate carbon dioxide absorption and moderate water vapor absorption) and $2060 \mathrm{~nm}$ (peak carbon dioxide absorption and low water vapor absorption) were selected for comparison of residuals produced by the reflectance, water vapor, solar zenith angle, sensor height, and aerosol simulation sets.

To determine the theoretical minimum detectable change in carbon dioxide concentration, residual radiance values for different carbon dioxide anomalies were compared to the noise equivalent delta radiance (NEdL) for AVIRIS C and AVIRIS NG. NEdL is the minimum change in radiance distinguishable from sensor noise and is dependent on both wavelength and radiance. NEdL values were calculated from sensorspecific radiometric models that included photon ("shot") and read noise for each spectral band. Detector quantum efficiency and throughput for each mirror and transmissive element were included in the radiometric models. At-sensor reflected solar radiance spectra modeled by MODTRAN for the $0 \mathrm{ppm}$ anomaly in each simulation set were used to model the NEdL spectra. It should be noted that NEdL does not account for all potential errors in imaging spectrometer data. Spectroscopic calibration, sensor alignment, and scanning artifacts can also introduce error into measured radiance.

\subsection{Plume detection}

NEdL establishes a minimum detection threshold for increased carbon dioxide concentration, however, it may be difficult to distinguish this signal when a spectrally heterogeneous background is present. To assess whether carbon dioxide plumes from power plants should be detectable in AVIRIS C data, concentrations modeled by a plume dispersion model were combined with a variable spectral background and a MODTRAN-generated look-up table to create simulated radiance images. The Cluster-Tuned Matched Filter (CTMF) detection algorithm (Funk et al., 2001; Thorpe et al., 2013) was then applied to the simulated radiance images. NEdL and background surface reflectance were varied to assess detection sensitivity to these factors. Finally, CTMF was used to demonstrate detection of carbon dioxide plumes in four AVIRIS $C$ radiance images possessing a variety spatial resolutions and atmospheric conditions (Table 3).

Matched filter algorithms are trained with a target spectrum to generate a linear weighting function that produces high values when an unknown spectrum matches the shape of the target spectrum. In this case, the target spectrum contains the residual radiance signal of increased carbon dioxide absorption. A CTMF approach can improve performance by first applying k-means clustering to partition the surface (background clutter) to minimize within-class variance, and then creating a matched filter that is specifically tuned for each cluster (Funk et al., 2001). In clustering pixels with similar radiance signatures, this approach assumes that the target radiance signal is a small contribution to the overall background covariance (Thorpe et al., 2013). CTMF uses a sample-based k-means algorithm on image principal components to assign extreme locations for class centroids. The number of k-means classes must be defined a priori and reflects a balance between maximizing the number of clusters to adequately classify an image, while maintaining enough pixels in each cluster to ensure adequate sample size.

After the k-means algorithm assigns clusters, a matched filter tuned for each cluster is applied to the image using the following equations:

$$
\begin{aligned}
& q_{j}=\frac{C_{j}^{-1} b}{\sqrt{b^{T} C_{j}^{-1} b}} \\
& f_{i, j}=q_{j}^{T} r_{i, j} .
\end{aligned}
$$

For class $j, q_{j}$ is the CTMF and represents an $n$-dimensional vector of optimal weights, where $n$ is the number of spectral bands (channels). $C_{j}^{-1}$ is the inverted $n$ by $n$ covariance matrix for the $j$ th class and $b$ is the

Table 3

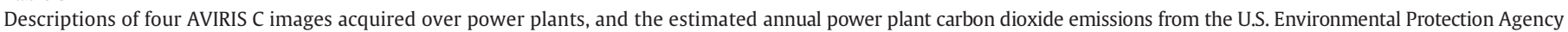

\begin{tabular}{|c|c|c|c|c|}
\hline Image & Mount Storm & New Madrid & Moss Landing & Jack Watson \\
\hline Latitude & 39.20 & 36.51 & 36.80 & 30.44 \\
\hline Longitude & -79.27 & -89.56 & -121.78 & -89.03 \\
\hline Date & $2008 / 7 / 2$ & $2011 / 7 / 27$ & $2011 / 9 / 28$ & 2011/10/13 \\
\hline Time (GMT) & 15.8 & 15.3 & 20.1 & 16.7 \\
\hline Solar azimuth & 122.7 & 104.4 & 182.5 & 157.5 \\
\hline Solar zenith & 25.5 & 39.8 & 38.9 & 40.7 \\
\hline Water vapor (mm) & 10.5 & 32.7 & 22.1 & 28.9 \\
\hline Sensor altitude (km) & 20.25 & 9.11 & 3.25 & 3.97 \\
\hline Ground elevation (m) & 995 & 91 & 8 & 4 \\
\hline Image spatial resolution (m) & 16.4 & 7.6 & 2.7 & 3.3 \\
\hline 2009 annual power plant emission $\left(\times 10^{6} \mathrm{Mg} \mathrm{CO}_{2}\right)$ & 9.5 & 6.6 & 1.8 & 2.8 \\
\hline
\end{tabular}
Emissions \& Generation Resource Integrated Database (eGRID) for 2009 (http://www.epa.gov/cleanenergy/energy-resources/egrid/index.html, last accessed March 2013). 
$n$-dimensional vector containing the target spectrum. The CTMF is multiplied by each image spectrum, $r_{i, j}$, a $n$-dimensional vector for the $i$ th pixel in class $j$ (Eq. 2), resulting in a CTMF score, $f_{i, j}$, for each pixel within the class. Multiplication by the inverted covariance matrix in the numerator in Eq. (1) 'whitens' the data, removing spectral crosscorrelation in the background clutter, while the denominator normalizes the filter so that the CTMF image has a variance of 1 when the signal is absent. The CTMF score for each pixel within a class is standardized, resulting in a mean CTMF score of 0 and standard deviation of 1 for the class. Filtered pixels are then recomposed as a final output image that reduced noise and sensitivity to surface features while enhancing the target spectrum signature. AVIRIS C spectra input into CTMF exclude the first four bands (365-395 nm), last three bands (2475-2500 nm), and strong water vapor absorption bands (1340-1495 nm, 1780-1960 nm) due to low signal. Otherwise, all bands are included for clustering and filtering.

Rather than tune the MODTRAN simulation parameters to match expected conditions in the simulated and real AVIRIS C images, a single
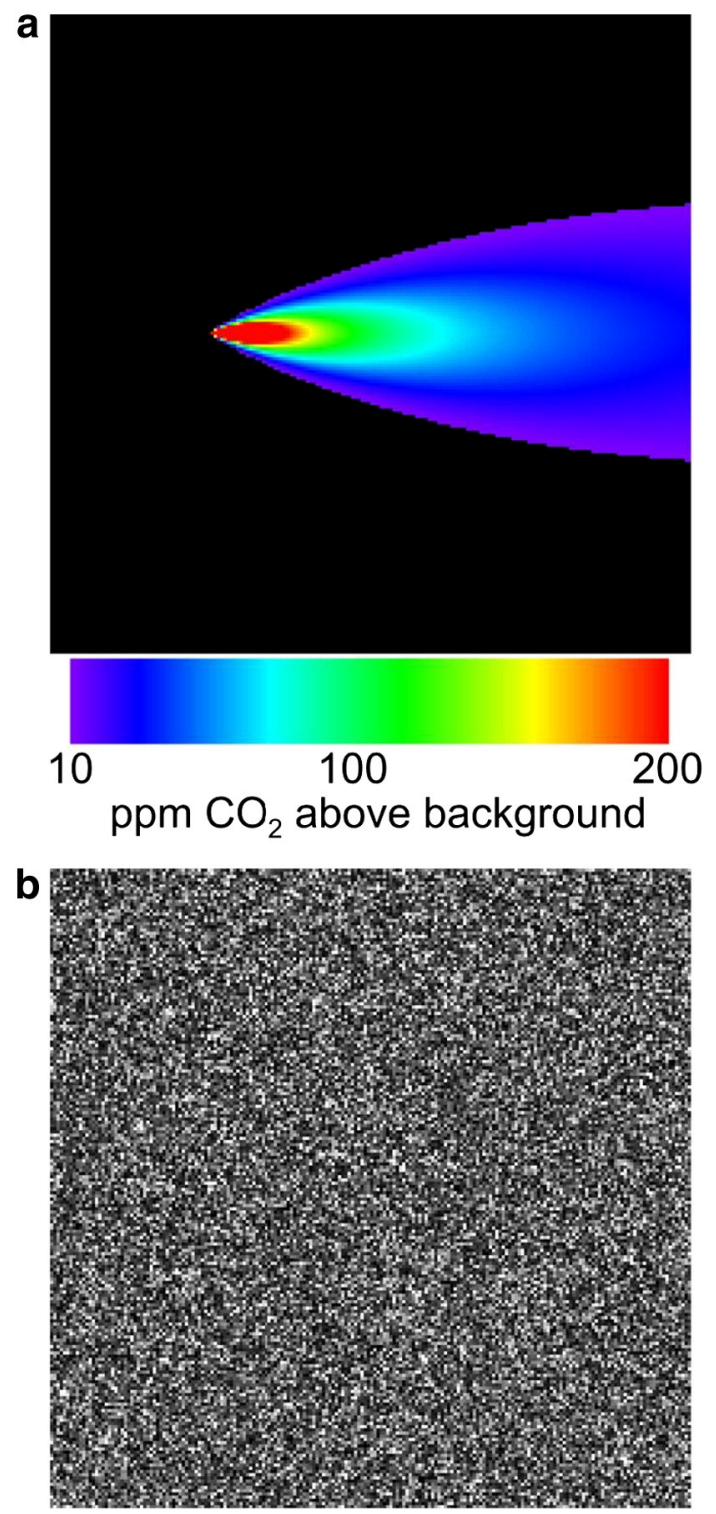

Fig. 2. (a) Carbon dioxide anomalies over a 500 m layer, for a $2 \mathrm{~km}$ by $2 \mathrm{~km}$ area, modeled by the plume dispersion model. Pixels with an anomaly less than $10 \mathrm{ppm}$ above background are shown in black. (b) A simulated radiance image showing the $2060 \mathrm{~nm}$ band for the same area as (a). Note that decreased radiance is not discernible within the area of the plume, due to the high variability of background reflectance. carbon dioxide residual radiance spectrum was used for the CTMF target spectrum. The baseline simulation set (15\% reflectance, $25 \mathrm{~mm}$ water vapor, $35^{\circ}$ solar zenith angle, $10 \mathrm{~km}$ sensor height, and $0.325 \tau_{a 550}$; see Table 1) was used to generate the residual radiance by subtracting simulated radiance with $100 \mathrm{ppm}$ carbon dioxide above background (within the 0-500 m layer) from simulated radiance for the background concentration. The resulting target spectrum was multiplied by negative one to produce positive CTMF scores that would correspond with increased carbon dioxide absorption.

CTMF was first applied to simulated image data containing a carbon dioxide anomaly modeled using a plume dispersion model (Fig. 2a). Generic parameters approximating a typical natural gas-fired power plant were used to create the plume dispersion model (ESI, 1971). The dispersion model used $10 \mathrm{~m}$ grid cells with a vertical height of $500 \mathrm{~m}$, and the plume was positioned within a $2 \mathrm{~km}$ by $2 \mathrm{~km}$ area. A simple bent-over Gaussian plume model with reflection at the ground surface was implemented closely following the (Hanna, Briggs, \& Hosker, 1982) plume rise model with a Pasquill-Gifford stability class $C$ for rural conditions and light to moderate winds (Briggs, 1973). Source strength was assumed to be 2 million metric tons of carbon dioxide per year $\left(63.4 \mathrm{~kg} \mathrm{~s}^{-1}\right)$, close to the minimum annual emissions of the four power plants captured in AVIRIS C images (Table 3). The wind speed at stack height $\left(U=3.6 \mathrm{~ms}^{-1}\right)$ was computed using a power law model with an exponent of 0.1 assuming $10 \mathrm{~m}$ winds of $3 \mathrm{~ms}^{-1}$. The stack was assumed to be $60 \mathrm{~m}$ tall with a radius $\left(R_{s}\right)$ of $2 \mathrm{~m}$. The concentration of emitted carbon dioxide $(c)$ was modeled as:

$$
\begin{aligned}
c(x, y, z)= & \frac{Q}{2 \pi U \sigma_{y} \sigma_{z}} \exp \left(\frac{-y^{2}}{2 \sigma_{y}^{2}}\right) \\
& \times\left(\exp \left(\frac{\left(z-h_{e}\right)^{2}}{-2 \sigma_{z}^{2}}\right)+\exp \left(\frac{\left(z+h_{e}\right)^{2}}{-2 \sigma_{z}^{2}}\right)\right) .
\end{aligned}
$$

In Eq. (3), $x, y$, and $z$ are coordinate distances in the along-wind, cross-wind and vertical directions respectively. $Q$ is the source strength $\left(\mathrm{kg} \mathrm{s}^{-1}\right)$ and the plume spread parameters (Briggs, 1973) are $\sigma_{y}$ and $\sigma_{z}$. $h_{e}$ is the effective height of the plume, and is equal to the stack height plus the plume rise $\left(h_{p r}(x)\right)$ at a distance $x$ downstream of the stack. The effective plume height was computed again following Hanna et al. (1982) as:

$h_{p r}(x)=\left(\frac{3 M}{\beta^{2} U^{2}} x+\frac{3 B}{2 \beta^{2} U^{3}} x^{2}\right)^{1 / 3}$.

In Eq. (4), the coefficient $\beta$ was taken as 0.6 following Briggs (1984). $M$ is the plume momentum flux and $B$ is the buoyancy flux. They are computed using Eqs. (5) and (6) respectively,

$B=g R_{s}^{2} V_{s} \frac{T_{e}-T_{a m b}}{T_{a m b}}$,

$M=R_{s}^{2} V_{s}^{2} \frac{T_{p}}{T_{a m b}}$.

In the above equations, $V_{s}$ is the stack exit velocity, $T_{p}$ is the plume temperature at the exhaust and $T_{a m b}$ is the ambient surrounding temperature. The ambient temperature was estimated as $303 \mathrm{~K}$ for a warm, slightly unstable day. The exhaust temperature and velocity were assumed to be $443 \mathrm{~K}$ and $13 \mathrm{~ms}^{-1}$ respectively, following information from ESI (1971).

Background reflectance for the simulated AVIRIS C images was based on a spectral library containing reflectance spectra for a variety of urban materials and vegetation species found in southern California, USA. Urban material spectra from Herold, Roberts, Gardner, and Dennison (2004) and vegetation spectra from Roberts et al. (1999) were collected in the field using an Analytical Spectral Devices full range field 
spectrometer (ASD Inc., Boulder, Colorado, USA). A total of 1659 spectra were used as the basis for a simulated reflectance image. All spectra were convolved to the 2011 AVIRIS C sensor response function. A 200 by 200 pixel image (covering $2 \mathrm{~km}$ by $2 \mathrm{~km}$ ) was created by assigning two random reflectance spectra from the library to each pixel. The first random spectrum was multiplied by a random fraction between 0 and 1, and the second endmember was multiplied by the reciprocal of the random fraction.

MODTRAN runs that varied carbon dioxide concentration and background surface reflectance were used to create a radiance lookup table. Carbon dioxide was varied from 0 ppm to 1500 ppm above background in $10 \mathrm{ppm}$ increments. Background surface reflectance was varied from $0 \%$ to $60 \%$ in $0.1 \%$ increments. All other factors were set to the values for the baseline simulation set listed in Table 1, producing a total of 90,751 modeled radiance spectra. Carbon dioxide concentration from the plume model and reflectance from the simulated reflectance image were used to look up the radiance value for each band in each pixel, which converted the simulated reflectance image into a simulated radiance image. A noise term based on AVIRIS C NEdL was then added to each band. The noise term was generated using a random Gaussian distribution, with NEdL assumed to represent one standard deviation. Finally, the simulated radiance image was converted to integer scaling using AVIRIS C gain factors (Fig. 2b).

The simulation sets listed in Table 1 revealed that NEdL and background surface reflectance were the two most important variables impacting detectability of carbon dioxide absorption at low-to-moderate solar zenith angles. To assess the sensitivity of plume detection to these two factors, NEdL was set to $0.33,1.0$, and 3.0 times the AVIRIS C NEdL for each band. Mean background surface reflectance at $2060 \mathrm{~nm}$ was adjusted to $6 \%, 12 \%$, and $24 \%$, where $12 \%$ is the approximate average of $2060 \mathrm{~nm}$ surface reflectance found under carbon dioxide plumes in the four AVIRIS C images (see Table 4). The CTMF was then applied to a total of nine simulated AVIRIS C radiance images containing the modeled carbon dioxide plume. Ten clusters were used for k-means clustering of all nine simulated radiance images.

True positive and false positive detection rates were determined using subsets of the simulated images. The true positive detection rate was calculated for 500 pixels containing a modeled carbon dioxide anomaly of $100 \mathrm{ppm}$ or greater (Fig. 2a). The false positive detection rate was calculated for 32,136 pixels containing an anomaly of less than $10 \mathrm{ppm}$, which is well below the detection threshold for AVIRIS data. Partial receiver operating characteristic (ROC) curves were generated using true positive and false positive detection rates for matched filter score detection thresholds ranging from +1 to +6 .

The CTMF was also applied to four AVIRIS C images acquired over fossil fuel power plants (Table 3). Spatial subsets of each AVIRIS C image containing 160,000 pixels were created. The subsets were processed to apparent surface reflectance using ACORN atmospheric correction software (ImSpec LLC) to retrieve average surface reflectance and atmospheric water vapor concentration within each image. A 2008 AVIRIS C image collected over the Mount Storm coal-fired power plant in West Virginia, USA had the highest sensor height, producing a geometrically corrected and resampled spatial resolution of $16.4 \mathrm{~m}$. The Mount Storm image also had the smallest solar zenith angle and the driest atmosphere (Table 3). All other AVIRIS C images were collected in 2011. An image acquired over the New Madrid coal-fired power

Table 4

Mean reflectance at $2000 \mathrm{~nm}$ and $2060 \mathrm{~nm}$ for contiguous areas of increased carbon dioxide absorption in each AVIRIS C image.

\begin{tabular}{lll}
\hline Image & Mean plume $\rho_{2000}$ & Mean plume $\rho_{2060}$ \\
\hline Mount Storm & 0.106 & 0.123 \\
New Madrid & 0.098 & 0.127 \\
Moss Landing & 0.143 & 0.157 \\
Jack Watson & 0.047 & 0.056 \\
\hline
\end{tabular}

plant in Missouri, USA had the highest atmospheric water vapor concentration. The geometrically corrected and resampled New Madrid image had an intermediate spatial resolution of $7.6 \mathrm{~m}$ (Table 3). The AVIRIS C image acquired over the natural gas-fired Moss Landing power plant in California, USA had the finest spatial resolution at $2.7 \mathrm{~m}$. An image collected over the coal-fired Jack Watson power plant in Mississippi, USA had a fine $3.3 \mathrm{~m}$ spatial resolution and the highest solar zenith angle (Table 3 ). The largest number of clusters that still maintained a minimum of 1000 pixels per cluster was used for the CTMF applied to each AVIRIS C image. Twenty-five clusters were selected for the Mount Storm, New Madrid, and Moss Landing subsets, while the Jack Watson subset used five clusters.

\section{Results}

\subsection{Radiance simulations}

As carbon dioxide concentration in the $0-500$ m layer was increased, residual radiance values also increased (Fig. 3). Several features associated with enhanced carbon dioxide absorption were evident. Residuals were strongest in two broad spectral regions: from 1530 to $1640 \mathrm{~nm}$ and from 1970 to $2090 \mathrm{~nm}$. Within those regions, residual radiance peaked at $1570 \mathrm{~nm}, 1600 \mathrm{~nm}, 2020$ and $2030 \mathrm{~nm}$, and again at 2060 and $2070 \mathrm{~nm}$. NEdL thresholds were exceeded at lower concentrations for the longer wavelength peaks. AVIRIS C NEdL was exceeded at a concentration anomaly of $100 \mathrm{ppm}$, while AVIRIS NG NEdL was exceeded at a lower anomaly of $25 \mathrm{ppm}$.

Residual radiance at 2000 and $2060 \mathrm{~nm}$ decreased linearly with decreasing surface reflectance. To better display the full range of residuals, residual radiance was plotted using a $\log _{10}$ scale on the $y$-axis of Fig. 4. Decreasing surface reflectance resulted in decreased at-sensor radiance and a correspondingly reduced residual radiance due to carbon dioxide absorption. NEdL also decreased with decreasing surface reflectance. At 20\% reflectance and $2000 \mathrm{~nm}$, the $100 \mathrm{ppm}$ residual exceeded AVIRIS C NEdL, while an anomaly in excess of $400 \mathrm{ppm}$ was necessary to exceed AVIRIS C NEdL at 2.5\% reflectance (Fig. 4a). Carbon dioxide anomalies as low as 50 ppm could theoretically be detected for high reflectance surfaces using AVIRIS C.

Because the absorption coefficient of water vapor is higher at $2000 \mathrm{~nm}$ than at $2060 \mathrm{~nm}$, residual radiance changed more rapidly with water vapor concentration at $2000 \mathrm{~nm}$ (Fig. 5). Sensitivity to carbon dioxide anomalies was highest for drier atmospheres, and decreased with increasing water vapor. NEdL also declined slightly with increasing water vapor, caused by increased water vapor absorption and reduced reflected radiance. At $2000 \mathrm{~nm}$, the $100 \mathrm{ppm}$ residual

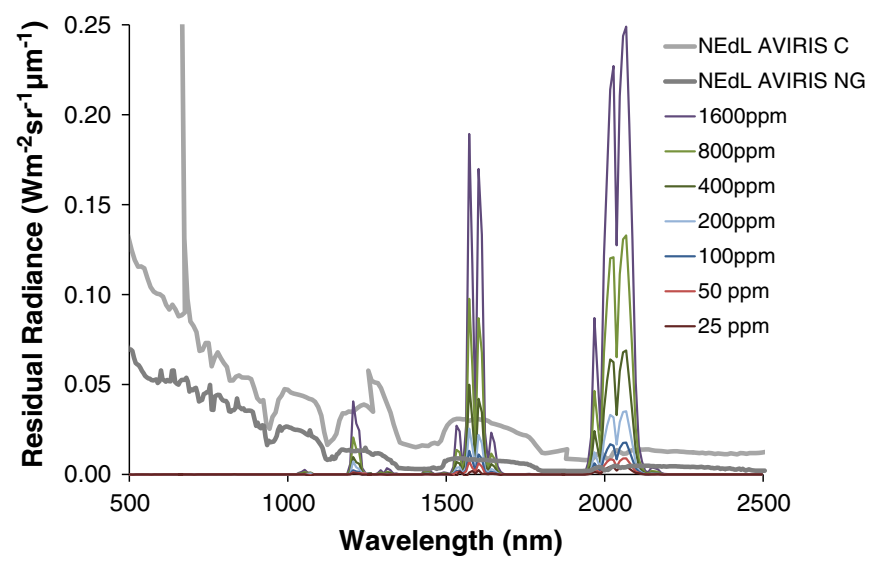

Fig. 3. Residual radiance across a range of carbon dioxide anomalies, compared to AVIRIS C and AVIRIS NG NEdL spectra. Carbon dioxide anomalies are for a 0-500 m layer. 
a

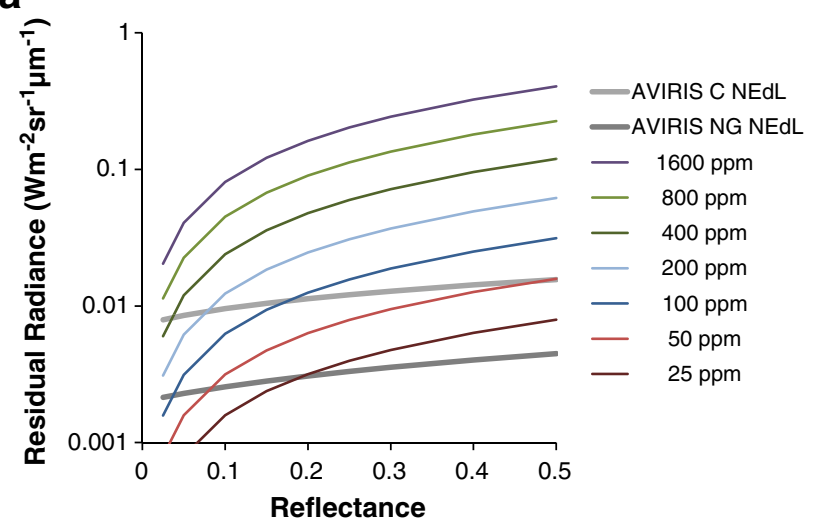

b

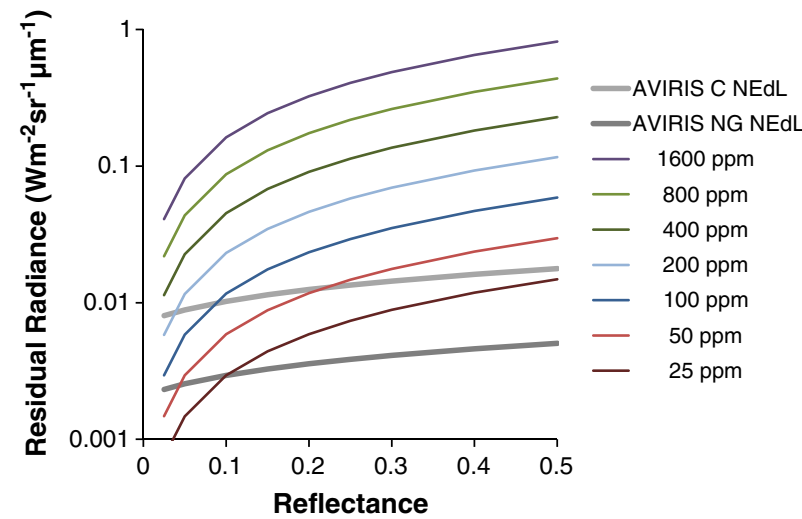

Fig. 4. Residual radiance across a range of surface reflectances for bands centered near $2000 \mathrm{~nm}$ (a) and $2060 \mathrm{~nm}$ (b). Carbon dioxide anomalies are for a 0-500 m layer.

exceeded the AVIRIS C NEdL threshold at $10 \mathrm{~mm}$ of water vapor (Fig. 5a), while the same anomaly produced a residual that was below the AVIRIS C NEdL threshold at $20 \mathrm{~mm}$ of water vapor.

Due to the increased atmospheric path length of solar irradiance, reduction of irradiance by the cosine of the incidence angle, and the relatively high absorption coefficient of carbon dioxide, solar zenith angle had a strong, non-linear effect on sensitivity to carbon dioxide anomalies (Fig. 6). Sensitivity to anomalies was highest at nadir, and decreased rapidly at solar zenith angles beyond $30^{\circ}$. At $70^{\circ}$ solar zenith angle, background carbon dioxide absorption was greatly enhanced by the long path length, which reduced sensitivity to carbon dioxide concentration anomalies in the $0-500 \mathrm{~m}$ layer. Water vapor absorption also increased with path length, which had a greater effect at $2000 \mathrm{~nm}$ than at $2060 \mathrm{~nm}$.

Path length was also a key factor in the simulation set that varied sensor height. Lower heights increased sensitivity to carbon dioxide anomalies, due to reduced background absorption from the surface to the sensor. At $100 \mathrm{ppm}$ and a sensor height of $0.5 \mathrm{~km}$, the residual radiance was above AVIRIS C NEdL at both wavelengths (Fig. 7). At $100 \mathrm{ppm}$ and a sensor height of $10 \mathrm{~km}$, only the $2060 \mathrm{~nm}$ band had a residual radiance that exceeded AVIRIS C NEdL. To ensure that changes in residual radiance remained visible for lower sensor heights, sensor heights above $20 \mathrm{~km}$ were omitted from Fig. 7. Residual radiance changed more slowly above $5 \mathrm{~km}$, and residuals at $100 \mathrm{~km}$ were effectively similar to those at $20 \mathrm{~km}$. With a constant surface reflectance, varying aerosol optical depth had relatively minor effects on sensitivity to carbon dioxide anomalies (Fig. 8). Scattering by aerosols is low in the SWIR, but scattering effects are more pronounced at $2000 \mathrm{~nm}$ where increased scattering is compounded by increased water vapor absorption.

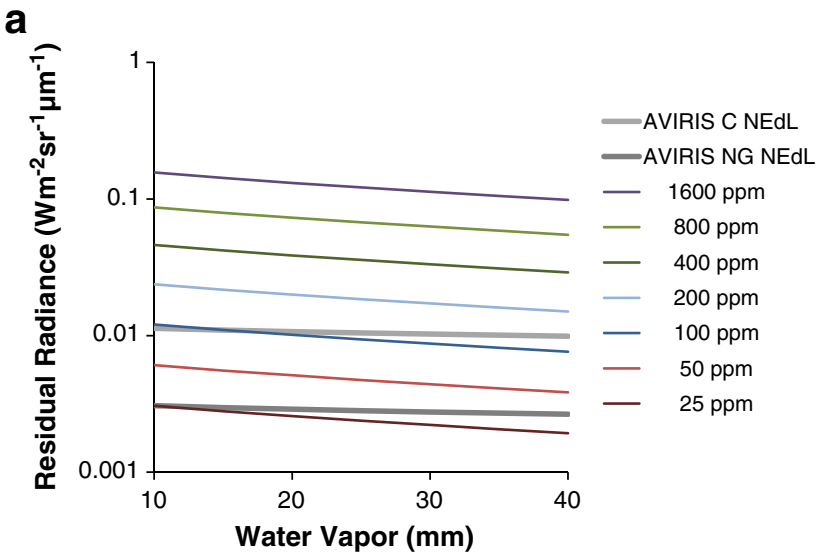

b

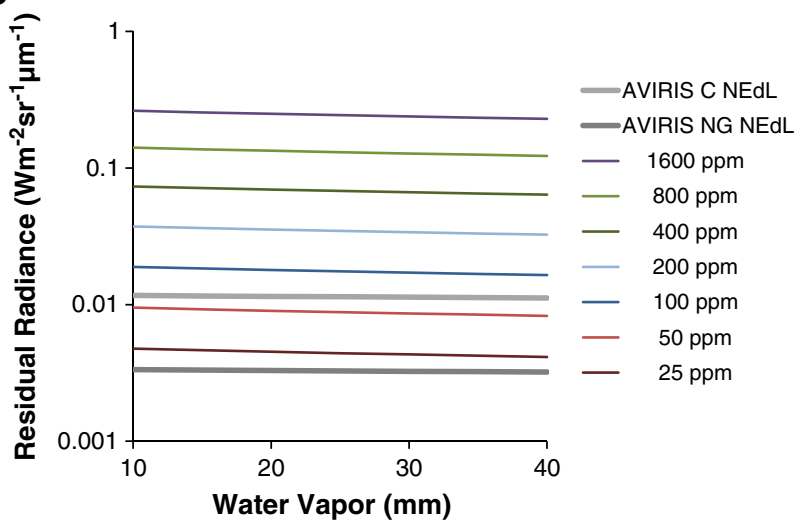

Fig. 5. Residual radiance across a range of water vapor concentrations for bands centered near $2000 \mathrm{~nm}$ (a) and $2060 \mathrm{~nm}$ (b). Carbon dioxide anomalies are for a 0-500 m layer.

\subsection{Plume detection in simulated images}

CTMF scores represent a standardized scale where strong positive scores indicate increased carbon dioxide absorption. Both NEdL and mean reflectance impacted the spatial extent of strong positive CTMF scores within the simulated images (Fig. 9). Only the portion of the plume with the highest carbon dioxide anomalies was detected in the simulated image with the highest noise $(3 \times$ AVIRIS C NEdL) and lowest reflectance (6\%). More of the plume was detected as NEdL decreased and reflectance increased. Based on the range of reflectance at $1 \times$ AVIRIS C NEdL, power plant carbon dioxide plumes produced by similar emission and atmospheric characteristics should be readily detectable in AVIRIS C data using CTMF. AVIRIS NG NEdL in the SWIR is approximately $1 / 3 \mathrm{rd}$ that of AVIRIS C. Fig. 9 demonstrates that AVIRIS NG should have improved ability to detect carbon dioxide plumes, even without accounting for the higher spectral resolution of AVIRIS NG.

True positive detection rates varied with the selected CTMF score detection threshold, but were highest for low NEdL and high background reflectance (Fig. 10). At a +1 CTMF score detection threshold, $24 \%$ mean background reflectance, and $0.33 \times$ AVIRIS C NEdL, the true positive detection rate peaked at $85 \%$. False positive detection rates were much lower than true positive detection rates. The false positive rate was highest for the simulated image with the highest NEdL and lowest reflectance. False positive rates decreased more rapidly than true positive rates as the CTMF score threshold was increased. At +1 , the average true positive rate across all simulated images was more than 6.5 times the false positive rate. At +2 , the average true positive rate was almost 38 times the false positive rate, and at +3 the average true positive rate was 372 times the false positive rate. However, using 
a

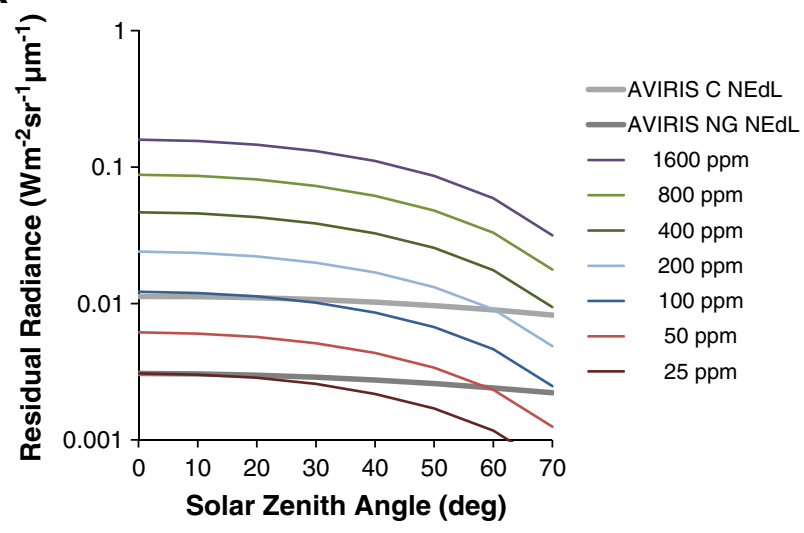

b

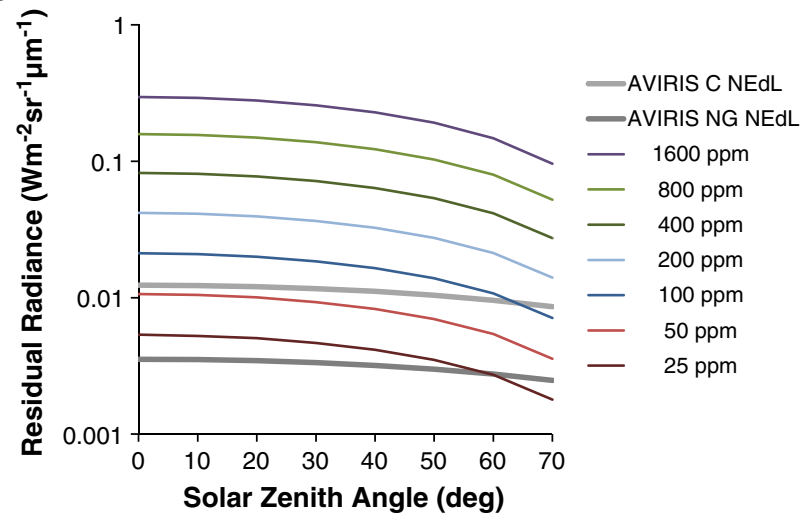

Fig. 6. Residual radiance across a range of solar zenith angles for bands centered near $2000 \mathrm{~nm}$ (a) and $2060 \mathrm{~nm}$ (b). Carbon dioxide anomalies are for a 0-500 m layer.

higher CTMF score detection thresholds also reduced true positive rates, averaging $40 \%$ at +2 and only $20 \%$ at +3 . True positive detection rates are strongly influenced by the selection of a minimum carbon dioxide anomaly, and true positive rates would decrease for anomalies below 100 ppm.

\subsection{Plume detection in AVIRIS C images}

Figs. 11-14 show the four AVIRIS C images, with part (a) of each figure displaying a true color composite and part (b) displaying CTMF scores. In all four AVIRIS C images, high CTMF scores in the immediate vicinity of power plants are clearly visible and indicate the likely presence of plumes with elevated carbon dioxide concentration.

The Mount Storm power plant was located on the east side (forward scattering geometry) of its AVIRIS C image, resulting in specular reflection off of the adjacent Mount Storm Lake (Fig. 11a). Surfaces within the image ranged from bare soil to forest cover. Sensor "slew", a known AVIRIS $C$ artifact produced when the instrument scans across areas of differing brightness (Montes, 2004), appears to have caused extreme low and high CTMF scores in several areas of the image. Sensor slew can increase or reduce measured radiance in carbon dioxide absorption bands. Although the changes in radiance are small, they are similar in magnitude and spectral shape to increased or decreased carbon dioxide absorption. This effect is clearly seen as a dark, linear feature in the upper right side of the CTMF image (Fig. 11b) and is caused by the sensor scanning across the edge between bright cleared land and dark forest.

A large, contiguous area with CTMF scores in excess of two was located over the power plant. The long axis of this feature was a

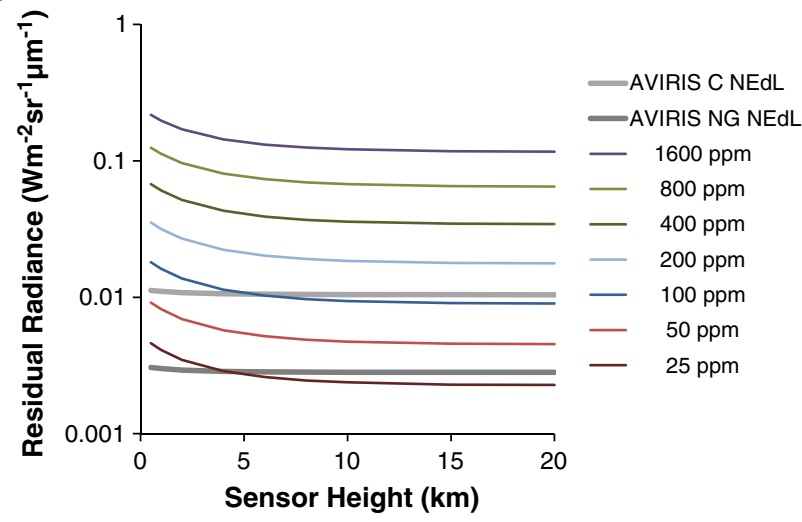

b

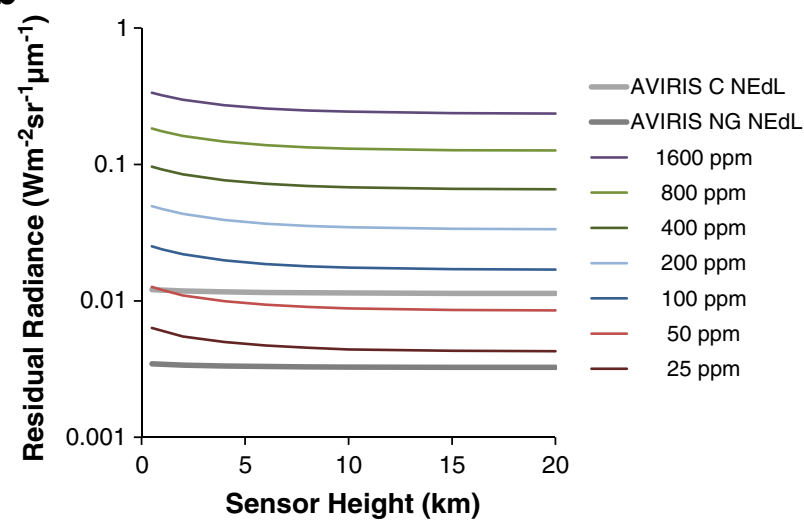

Fig. 7. Residual radiance across a range of sensor heights for bands centered near $2000 \mathrm{~nm}$ (a) and $2060 \mathrm{~nm}$ (b). Values above $20 \mathrm{~km}$ are not shown. Carbon dioxide anomalies are for a 0-500 m layer.

approximately $500 \mathrm{~m}$ long, and extended to the east from the power plant to Mount Storm Lake. Due to the lack of wind observations within this sparsely populated area and the relatively coarse resolution of the image, it is difficult to irrefutably demonstrate that this feature was in fact a carbon dioxide plume, but the feature is consistent with increased carbon dioxide absorption. Water vapor within the plume emanating from the power plant would result in a reduced expression of carbon dioxide absorption (Fig. 5), and cannot be solely responsible for the pattern in the CTMF scores. This feature crosses a variety of surfaces (Fig. 11a) and the average reflectance within the region of high CTMF scores was $10.6 \%$ at $2000 \mathrm{~nm}$ and $12.3 \%$ at $2060 \mathrm{~nm}$ (Table 4).

High CTMF scores in the New Madrid image are also consistent with a carbon dioxide plume (Fig. 12b). Two roughly parallel carbon dioxide absorption anomalies extend approximately $400 \mathrm{~m}$ north of the power plant towards the Mississippi River. The smoke plume from the power plant is visible over the dark water of the Mississippi River in the same direction as the carbon dioxide anomalies. The use of only one operational smoke stack at New Madrid rules out two discrete, parallel plumes. Only one plume is emitted from a $244 \mathrm{~m}$ smokestack at the plant, but the carbon dioxide absorption anomalies are separated due to solar-view geometry. The feature on the right results from solar irradiance reflected off of the surface that subsequently passes through the plume to the sensor. The feature on the left is produced by solar irradiance first passing through the plume, then reflecting off of the surface and to the sensor. The separation of the two features was aided by the tall height of the smokestack and the high solar zenith angle $\left(39.8^{\circ}\right)$. The lower end of the right feature is aligned with the smokestack, while the lower end of the left feature is aligned with the shadow of the smokestack, which is faintly visible at the "eight o'clock" position on the yellow circle in 
a

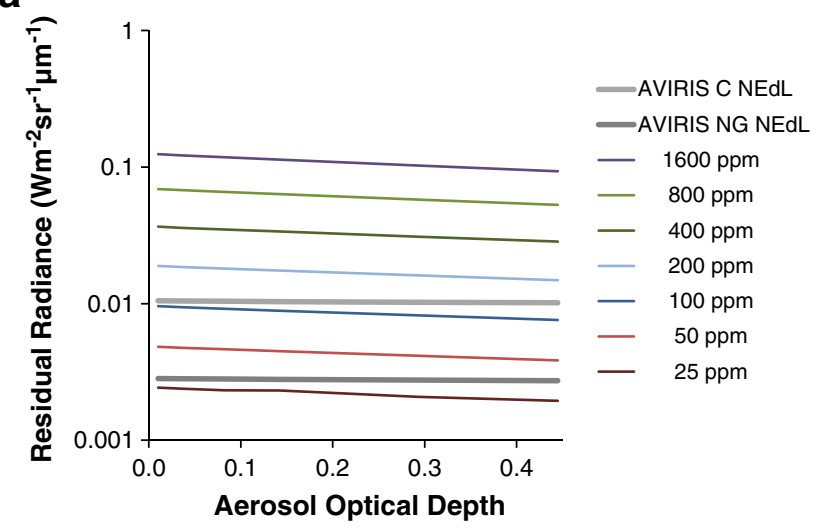

b

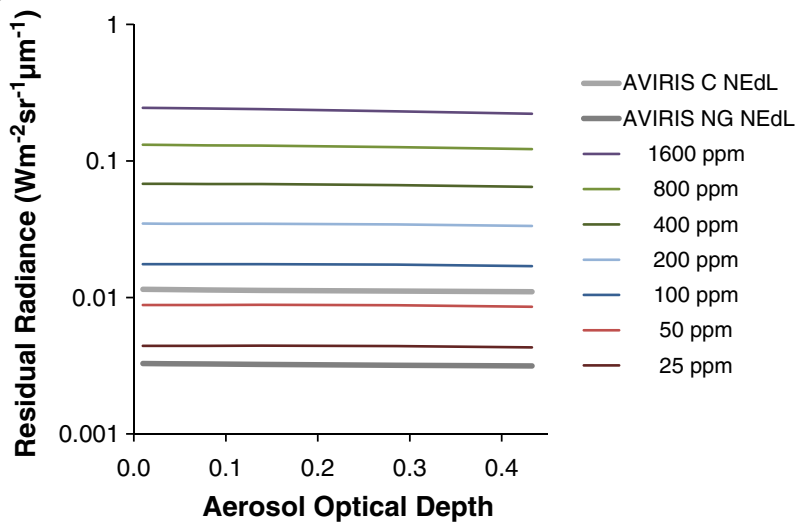

Fig. 8. Residual radiance across a range of aerosol optical depths for bands centered near $2000 \mathrm{~nm}$ (a) and $2060 \mathrm{~nm}$ (b). Aerosol optical depth values are specific to each wavelength. Carbon dioxide anomalies are for a 0-500 m layer.
Fig. 12a. Both features are perpendicular to the shadow and the solar azimuth. The distance between the two features closest to the source is 28 pixels, approximately equal to an expected distance of 27 pixels based on solar zenith angle, stack height, and image resolution. Average reflectance within the area contained by the two carbon dioxide absorption features was slightly lower than Mount Storm at $2000 \mathrm{~nm}$, but slightly higher at $2060 \mathrm{~nm}$ (Table 4).

The Moss Landing image had the finest spatial resolution, at $2.7 \mathrm{~m}$. As a result, the Moss Landing power plant and plume are resolved in much higher detail (Fig. 13). A plume-shaped carbon dioxide absorption anomaly is clearly visible in Fig. 13b. The highest CTMF scores extend for approximate $500 \mathrm{~m}$ east of the power plant, and more subtle increases carbon dioxide absorption continue to the edge of the image. Although no wind speed was measured at the closest available weather observation $5 \mathrm{~km}$ inland from the power plant, the feature is consistent with a typical westerly on-shore wind. It is not obvious whether multiple plumes are present or whether one-way absorption dominates as in the case of New Madrid. However, there are short, separate stacks for each of four generators on the site, and the plume features are not exactly perpendicular to the solar azimuth angle as seen in the New Madrid image. These factors make it more likely that the high CTMF scores are caused by two-way absorption or mixed one-way and two-way absorption. Reflectance in the area of the plume was relatively high due to concrete and senesced grass surfaces beneath the plume (Table 4).

The Jack Watson image shares many similarities with the New Madrid scene (Fig. 14). Two roughly parallel areas of high CTMF scores extend to the east of the power plant. The origin points of the two features align with solar azimuth (Table 3), and the solar zenith angle is close to $40^{\circ}$. Like New Madrid, a single, tall stack is present at this power plant, so the resulting absorption anomalies must result from one-way absorption. Unlike New Madrid, the plume shadow (solar irradiance that passes through the plume and then reflects off the ground, seen as the upper left feature in Fig. 14b) appears to have the highest CTMF scores near the plume source. The closest recorded wind observation measured a $1.5 \mathrm{~ms}^{-1}$ wind from $240^{\circ}$ approximately $10 \mathrm{~min}$ after the image was acquired. This wind direction roughly aligns with the apparent

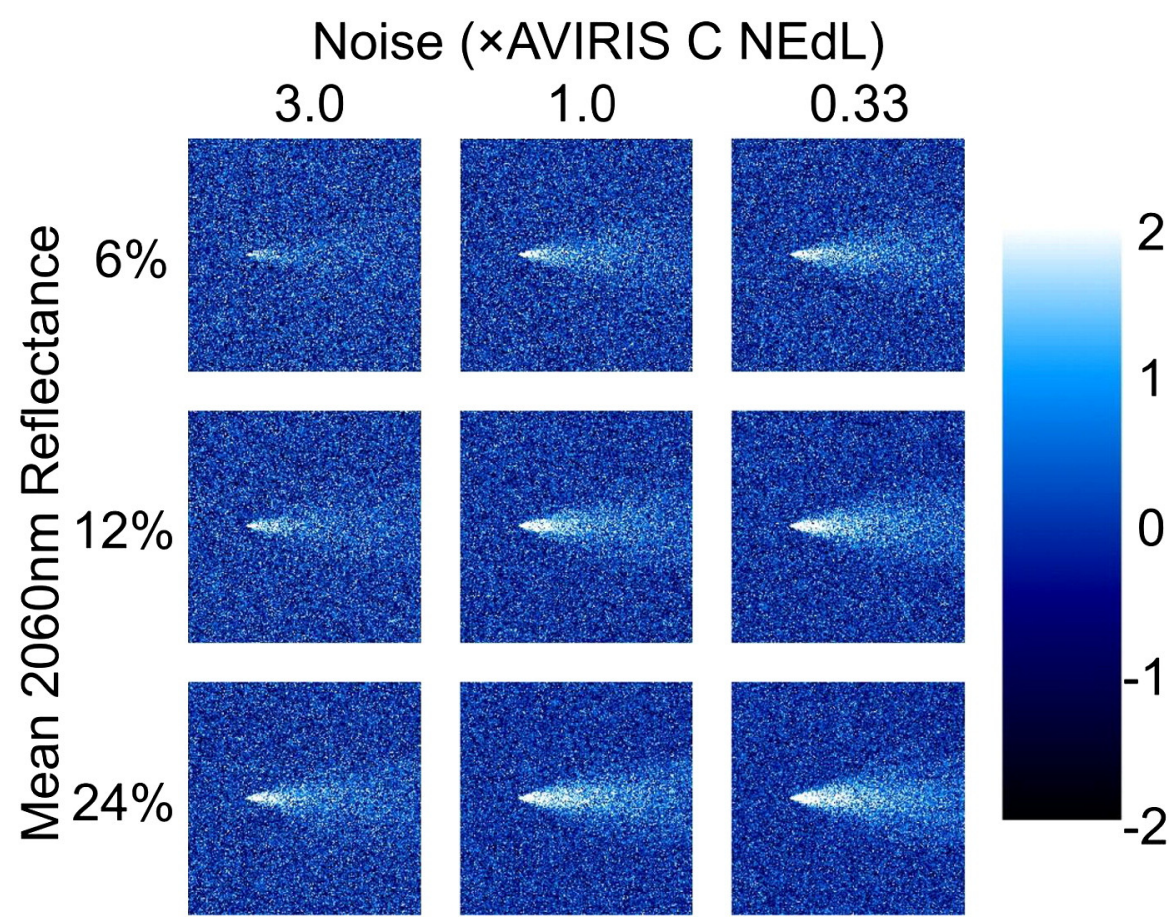

Fig. 9. CTMF scores for the modeled plume shown in Fig. 2a, over a simulated image background with varying NEdL and mean background reflectance. 


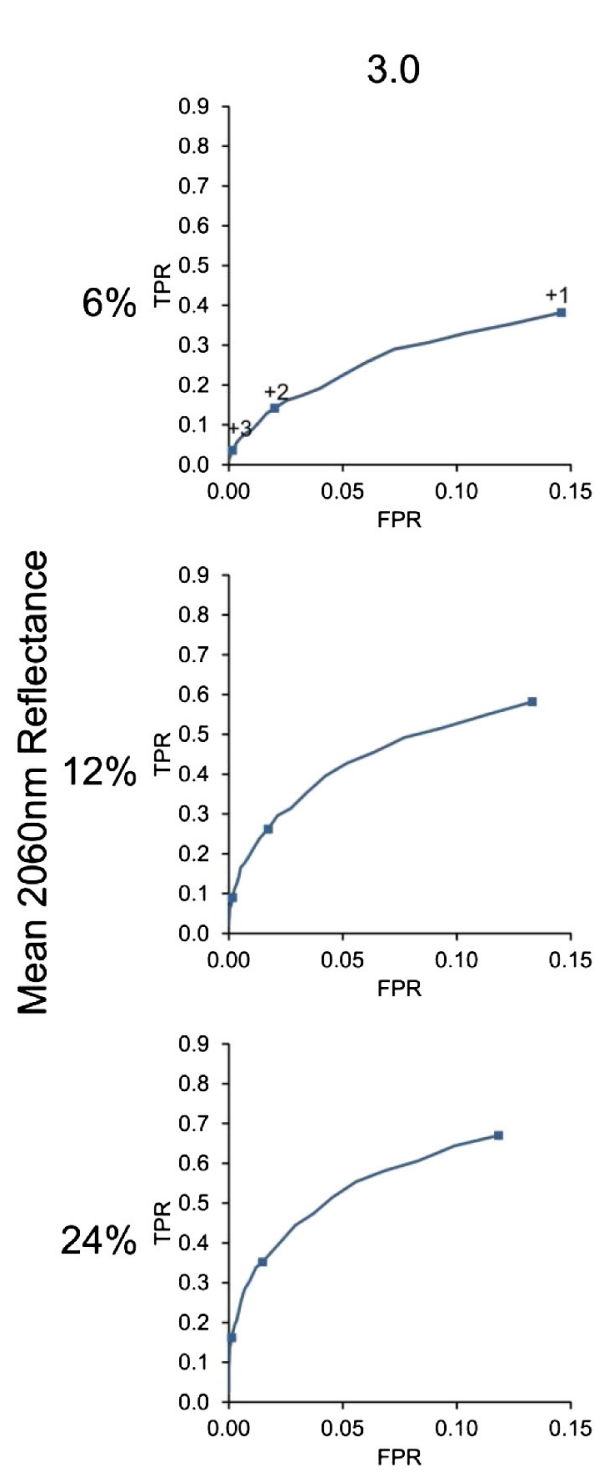

Noise ( $\times$ AVIRIS C NEdL)
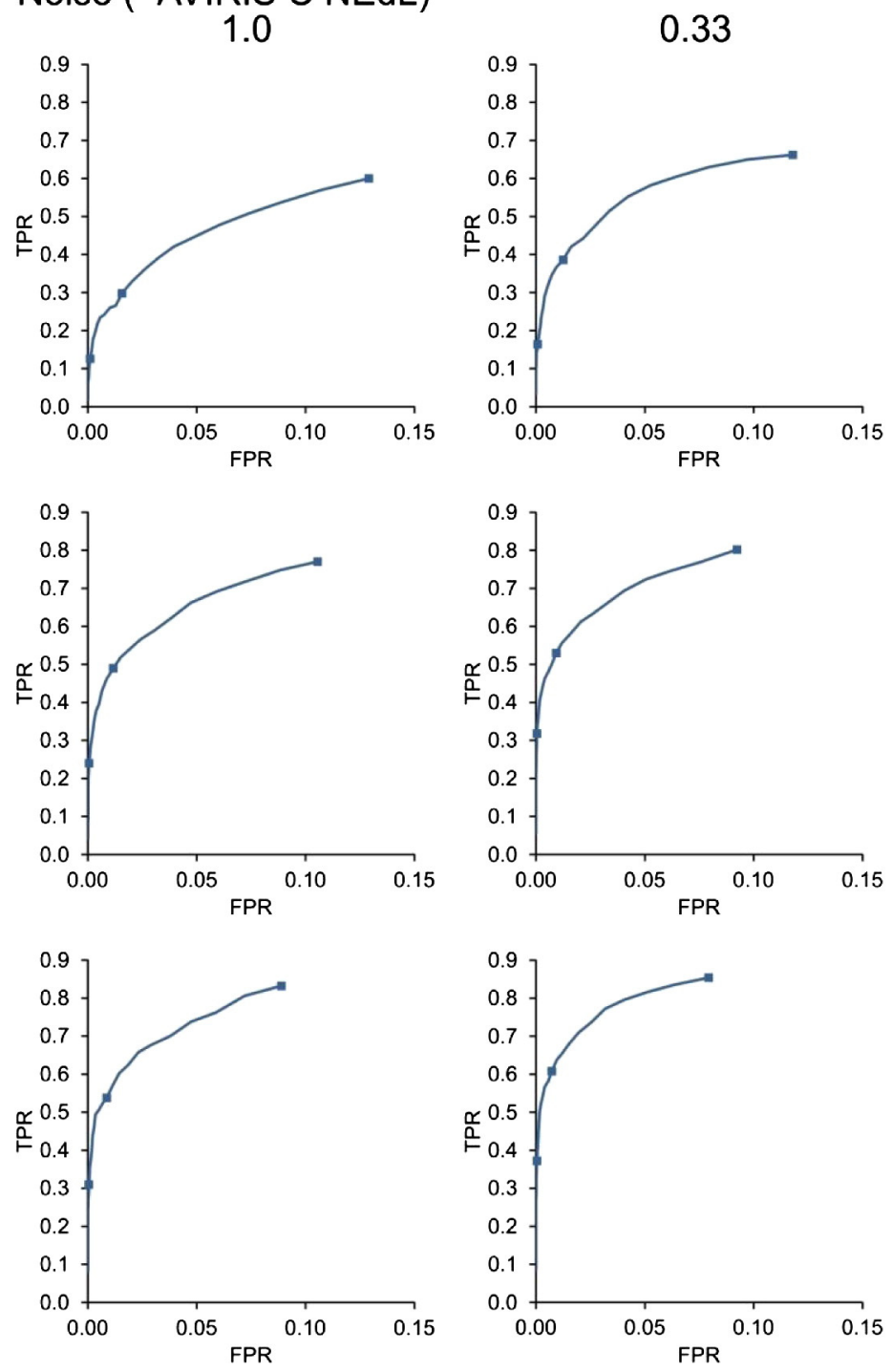

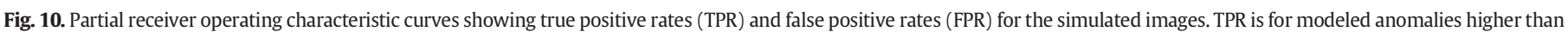

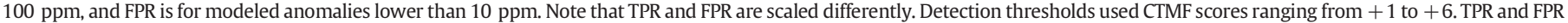
at CTMF score detection thresholds of $+1,+2$, and +3 are marked by points.

direction of plume travel in Fig. 14b. The reflectance of the area beneath the plume was much lower than the other three AVIRIS C images, with average reflectance below 5\% at $2000 \mathrm{~nm}$ and below 6\% at $2060 \mathrm{~nm}$ due to a large coal pile and forest downwind of the power plant (Table 4).

\section{Discussion}

The New Madrid and Jack Watson images reveal a discrepancy between the MODTRAN simulation sets, simulated images, and spectrally-expressed absorption within some AVIRIS C images. A combination of tall smoke stacks at these two plants and high solar zenith angles resulted in two discrete features; one caused by solar irradiance reflecting off the surface and then through the plume, and a second "plume shadow" caused by solar irradiance transmitted through the plume and reflected off of the surface. The MODTRAN simulation sets and simulated images assumed two-way absorption and did not explicitly separate the downwelling and upwelling paths. One-way absorption will result in a reduced expression of a carbon dioxide anomaly, making detection more difficult. Discrete separation of plume and plume shadow may be advantageous, however, since one-way and two-way absorption may not be reliably distinguishable where the plume and plume shadow overlap. Multiple images acquired from different view zenith and azimuth angles, and/or as solar zenith and azimuth change, could help resolve plume geometry.

Aerosols and cirrus clouds have been shown to be major sources of uncertainty in carbon dioxide retrievals for GOSAT, SCIAMACHY, and OCO (Boesch, Baker, Connor, Crisp, \& Miller, 2011; Butz, Hasekamp, Frankenberg, \& Aben, 2009; Guerlet et al., 2013; Houweling et al., 2005). Our simulations showed that for a fixed reflectance, aerosols had a relatively minor impact on carbon dioxide residual radiance at 2000 and $2060 \mathrm{~nm}$ (Fig. 8). Examination of changes in residuals at additional wavelengths and in conjunction with variable background surface reflectance could reveal stronger aerosol effects. Plumes emitted by coal-fired power plants are likely to produce substantial aerosol scattering within the plume itself. This scattering should be examined as a potential source of error in carbon dioxide anomaly detection and concentration retrieval at fine spatial scales. The effects of cirrus clouds on anomaly detection using imaging spectrometer data should also be determined.

AVIRIS NG provides several important advantages over AVIRIS C for detection of elevated carbon dioxide concentrations. AVIRIS NG is a pushbroom instrument capable of flying at lower altitude without 

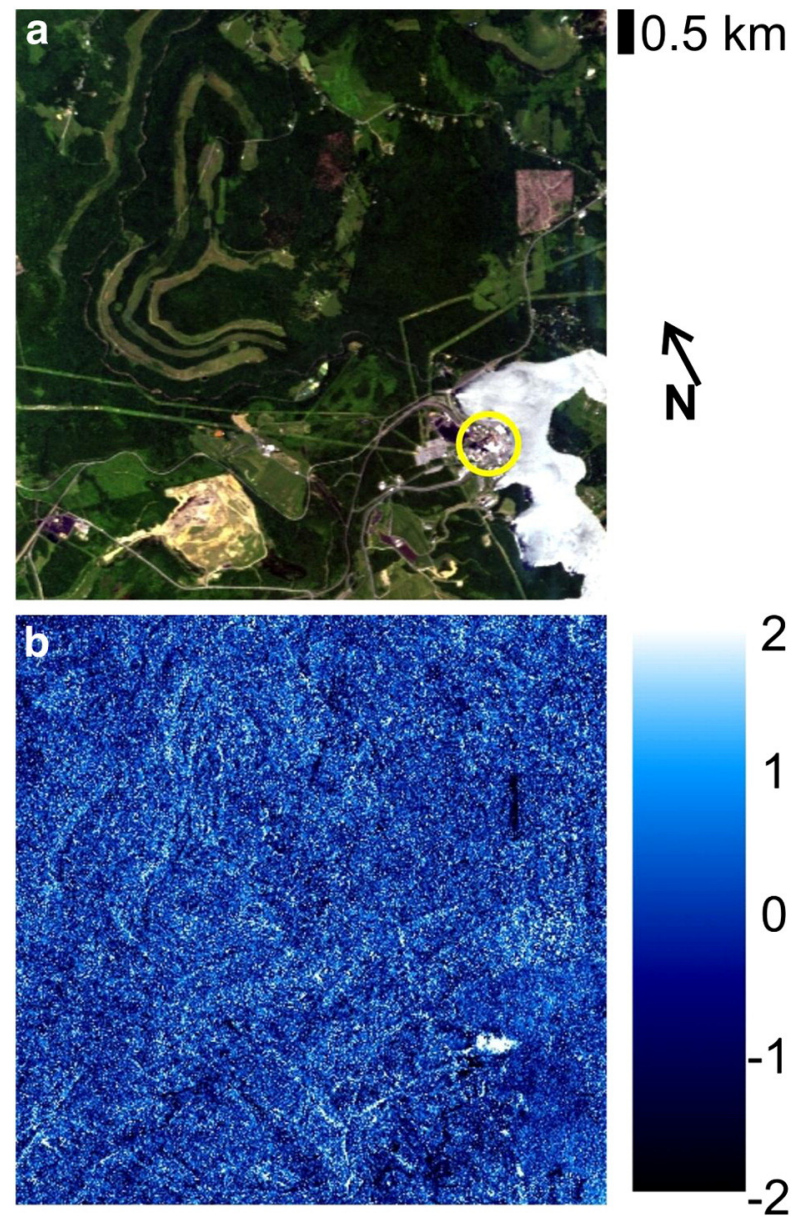

Fig. 11. a) A true color composite of a 2008 AVIRIS C image. Mount Storm power plant is in the lower right portion of the image, with the location of the stack indicated by the circle. b) CTMF scores for the same AVIRIS C image.

undersampling. Lower altitude will provide higher spatial resolution and improved ability to map carbon dioxide plumes (e.g. Fig. 13). As a pushbroom instrument, AVIRIS NG will eliminate the slew effect that caused the CTMF to detect carbon dioxide anomalies at edges between bright and dark surfaces. AVIRIS NG will also have an improved $5 \mathrm{~nm}$ spectral resolution, which may better resolve carbon dioxide absorption features in the SWIR. Most importantly, AVIRIS NG will have a higher signal-to-noise ratio, resulting in SWIR NEdL approximately one third that of AVIRIS C. This will provide improved sensitivity to low residual radiance values, increasing true positive detection rates (Fig. 10) and allowing detection of lower carbon dioxide anomalies (Fig. 9).

The proposed spaceborne HyspIRI VSWIR sensor will have a similar sensor response function and spectral resolution as AVIRIS C. With a 19day repeat period and global mapping capabilities, HyspIRI VSWIR data may be useful for detection of carbon dioxide anomalies. The tradeoff for HyspIRI VSWIR is a $60 \mathrm{~m}$ spatial resolution, which is considerably coarser than the spatial resolution of the Mount Storm AVIRIS C image (Fig. 11). VSWIR data will also contain a much greater diversity in background reflectance, in terms of both magnitude and spectral shape. This variability will make robust detection of carbon dioxide anomalies more difficult, and surfaces that could result in false positive anomalies due to their spectral shape should be investigated.

Spinetti et al. (2008) applied a continuum interpolated band ratio (CIBR) to AVIRIS C data to retrieve carbon dioxide concentrations from a plume produced by the Pu'u'O'o volcanic eruption in Hawai'i. MODTRAN was used to simulate radiance spectra with varying column carbon dioxide concentration, water vapor concentration, and aerosol

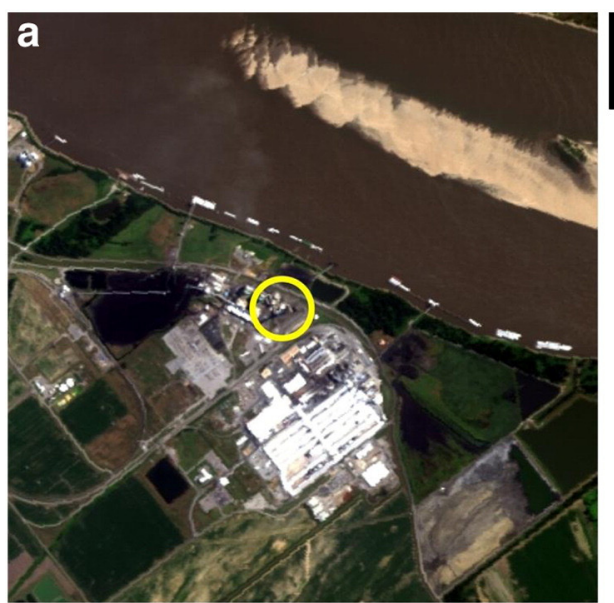

$0.5 \mathrm{~km}$

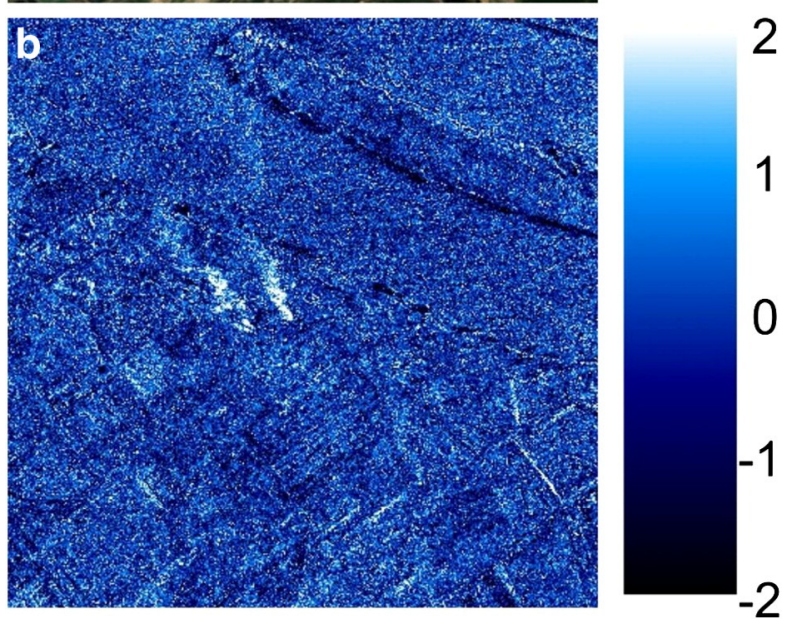

Fig. 12. a) A true color composite of a 2011 AVIRIS C image. New Madrid power plant is in the center of the image, with the location of the stack indicated by the circle. b) CTMF scores for the same AVIRIS C image.

optical depth. Calibration curves for a CIBR centered over a $2011 \mathrm{~nm}$ carbon dioxide absorption maximum were derived from the MODTRAN generated spectra, and the curve coefficients were used to invert CIBR values from the AVIRIS C image to produce carbon dioxide concentration. Concentrations ranging from 40 to $350 \mathrm{ppm}$ above background were reported. Column concentrations in this range should be detectable in AVIRIS C data based on our results. Our tests indicate that the Spinetti et al. (2008) CIBR is not as effective for detection of carbon dioxide plumes over spectrally heterogeneous backgrounds. The Spinetti et al. (2008) CIBR was applied to the four power plant images, and no plume-like anomalies were found (e.g. Fig. 15). CTMF uses a complete target spectrum, and is thus less sensitive to variable background reflectance and noise. The CIBR approach uses only one carbon dioxide absorption band and two reference bands, reducing the sensitivity of the resulting index to absorption anomalies. CTMF is also able to accommodate variable background reflectance through clustering. The dependence of both residual radiance and NEdL on surface reflectance highlights the importance of detection methods that can accommodate spectrally- and spatially-variable reflectance. For spectrally- and spatially-homogeneous surfaces, index-based approaches for detection and concentration retrieval (e.g. Bradley et al., 2011; Spinetti et al., 2008) may still be appropriate.

Detection of carbon dioxide plumes in AVIRIS images is a first step towards retrieval of carbon dioxide concentrations within plumes. Several additional advances are required before concentration retrieval can be attempted. Radiative transfer modeling must take into account specific 

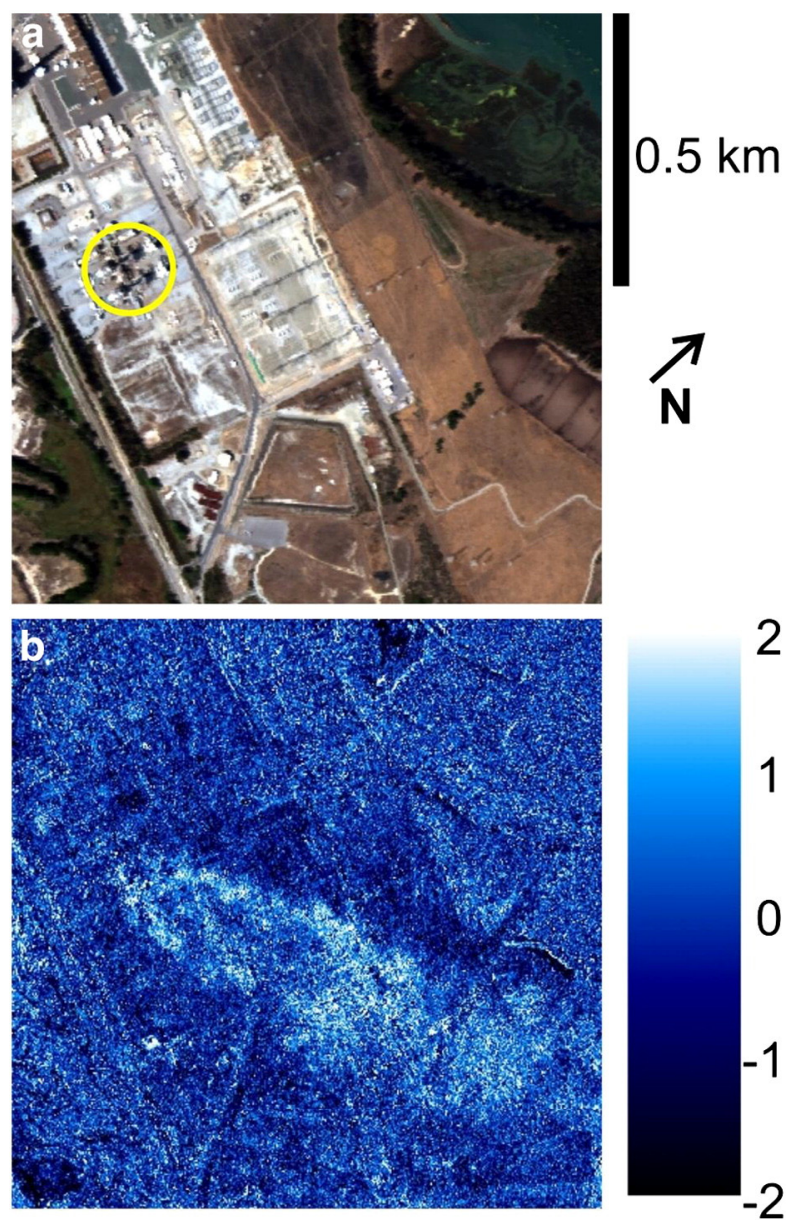

Fig. 13. a) A true color composite of a 2011 AVIRISC image. Moss Landing power plant is in the center left portion of the image, with the location of four stacks indicated by the circle. b) CTMF scores for the same AVIRIS C image.

solar, view, and plume geometries, and resolve one-way and two-way absorption if necessary. Background surface reflectance will also need to be taken into account, both for calculating residual radiance and matching residual radiance values using radiative transfer modeling. While this study examines minimum carbon dioxide anomalies required for detection of plumes, additional work is needed to determine measurement precision across the expected range of carbon dioxide concentrations. A combination of plume dispersion modeling and sampling of plume vertical profiles may assist in validating plume concentrations retrieved from imaging spectrometer data. Unlike coarser spatial resolution instruments, airborne imaging spectrometers should be able to resolve plume structure for comparison with modeled plume dispersion.

\section{Conclusions}

Sensitivity to carbon dioxide anomalies was greatest for high reflectance, low water vapor, low solar zenith angle, low sensor height, and low aerosol optical depth. For the scenarios tested in this paper, 0 $500 \mathrm{~m}$ carbon dioxide anomalies as low as $100 \mathrm{ppm}$ (5.6 ppm column anomaly) above background for AVIRIS C and 25 ppm (1.4 ppm column anomaly) above background for AVIRIS NG produced residual radiance values that exceeded sensor NEdL. Minimum anomalies needed for accurate detection of plumes will depend on the expressed magnitude and spectral shape of the anomaly in imaging spectrometer data. Due to high spectral and spatial variability, NEdL and background surface
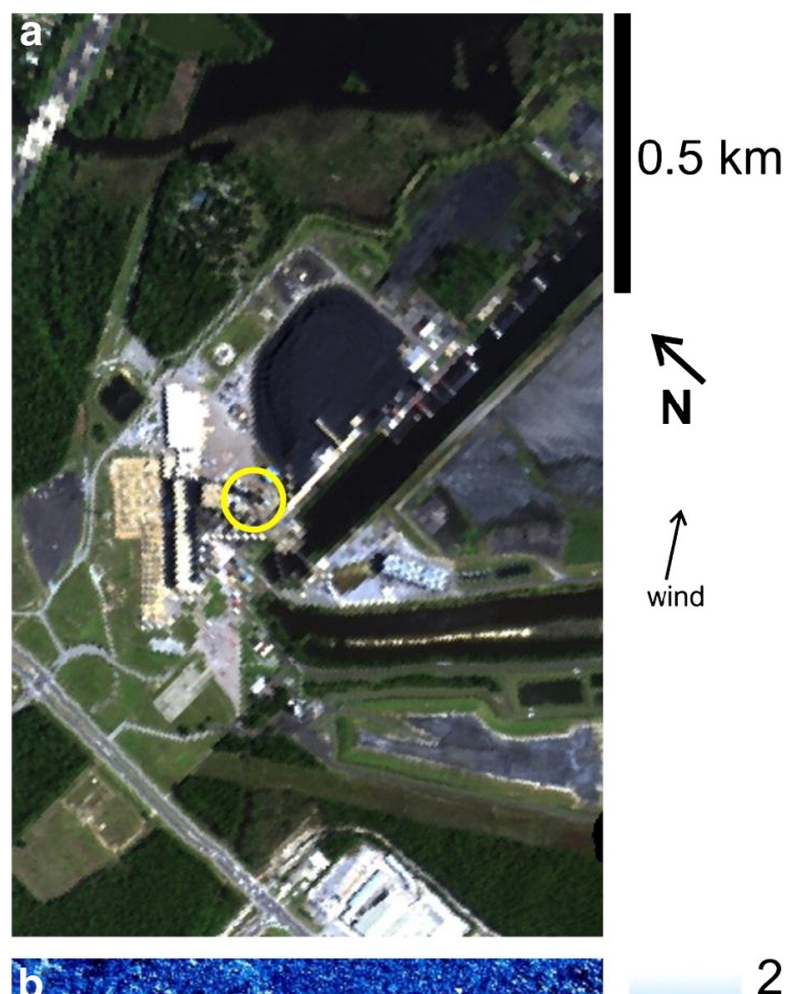

2

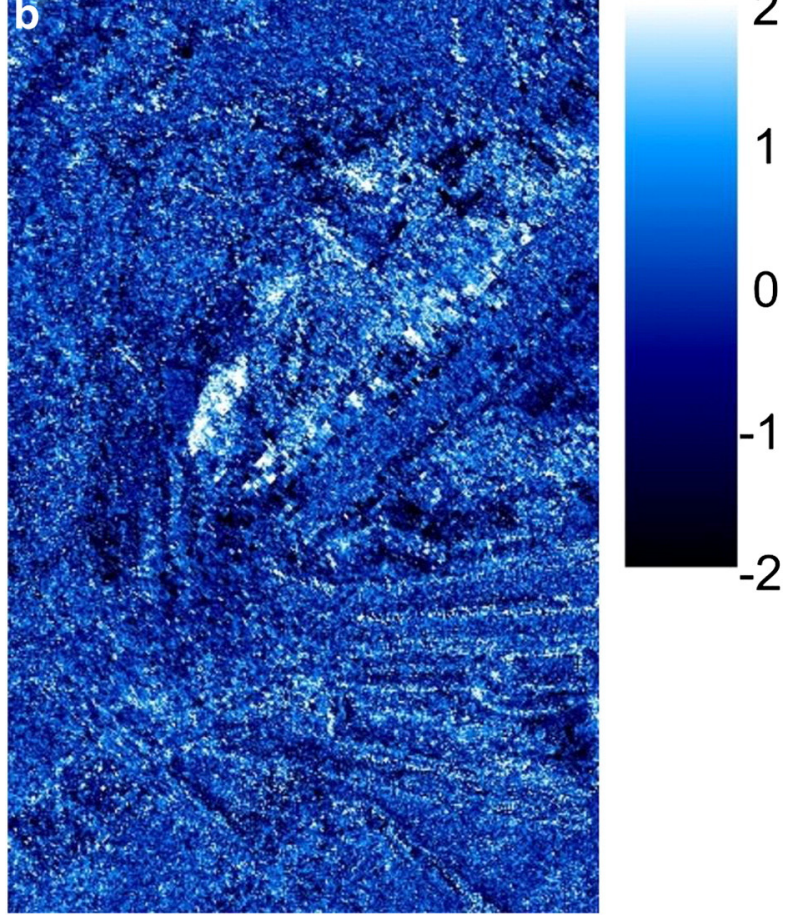

Fig. 14. a) A true color composite of a 2011 AVIRIS C image. Jack Watson power plant is in the center of the image, with the location of the stack indicated by the circle. b) CTMF scores for the same AVIRIS C image.

reflectance are particularly important for determining sensitivity to carbon dioxide anomalies. Carbon dioxide anomalies will have reduced detectability when signal-to-noise ratio is low and over dark surfaces. Detection will be aided by high signal-to-noise and bright, spectrally flat, and homogeneous surfaces. Spectral and spatial variation in reflectance will likely further increase the minimum anomaly needed for detection. Development of concentration retrieval algorithms will need to account for both background reflectance and solar-plume-view geometry. 


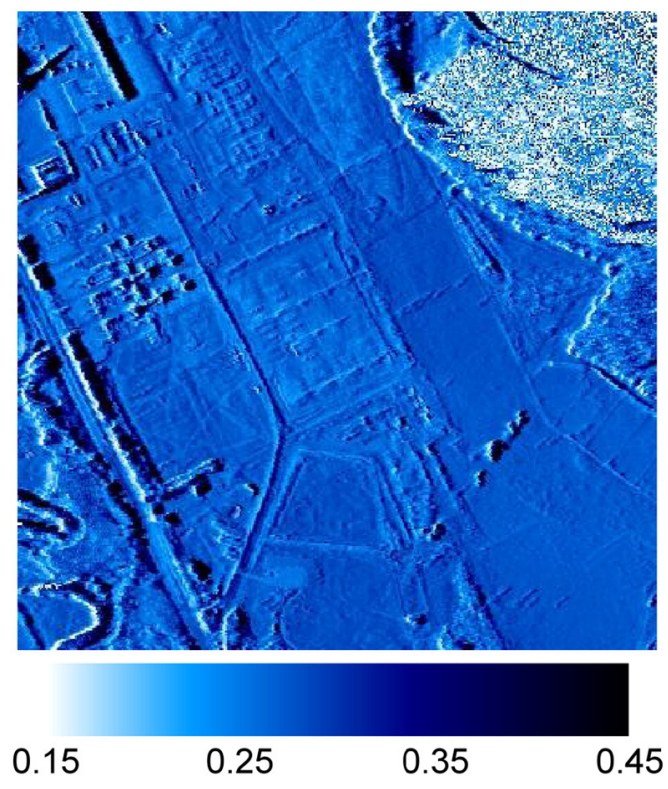

Fig. 15. Spinetti et al. (2008) CIBR values for the 2011 AVIRIS C image acquired over the Moss Landing Power Plant. The true color composite and CTMF scores for the same area are shown in Fig. 12. Lower CIBR values (brighter tones) indicate increased carbon dioxide absorption.

With improvements in detection and concentration retrieval algorithms, imaging spectrometer data may provide a valuable means for measurement of point source carbon dioxide emissions and scaling to global satellite measurements. By design, current and planned satellite missions dedicated to global mapping have much higher concentration retrieval precision than will be possible with a general purpose imaging spectrometer. For example, science requirements for OCO-2 specify a column concentration accuracy of 1 ppm (Crisp et al., 2004), well below the anomaly detection threshold for AVIRIS NG. However, airborne imaging spectrometers do offer complementary abilities including high spatial resolution, sensitivity to multiple trace gases (Dennison, Thorpe, Roberts, \& Green, 2013; Thorpe et al., 2013), and the ability to target specific sites or areas. The combination of coarse-scale satellite data and fine-scale imaging spectrometer data could reduce uncertainty in anthropogenic greenhouse gas emissions and improve understanding of the global carbon budget.

\section{Acknowledgments}

We would like to acknowledge the assistance of Lex Berk of Spectral Science, Inc. in developing the MODTRAN simulations. Partial funding for this research was provided by NASA grant \#NNX13AK85A.

\section{References}

Ackerman, K. V., \& Sundquist, E. T. (2008). Comparison of two US power-plant carbon dioxide emissions data sets. Environmental Science \& Technology, 42, 5688-5693.

Ben-Dor, E., \& Kruse, F. A. (1996). Detection of atmospheric gases using GER 63 channel scanner data acquired over Makhtesh Ramon, Negev Israel. International Journal of Remote Sensing, 17, 1215-1232.

Berk, A., Anderson, G. P., Acharya, P. K., Bernstein, L. S., Muratov, L., Lee, J., et al. (2005). MODTRAN 5: A reformulated atmospheric band model with auxiliary species and practical multiple scattering options: Update. In S. S. Sylvia, \& P. E. Lewis (Eds.), Algorithms and technologies for multispectral, hyperspectral, and ultraspectral imagery XI. Bellingham, WA: Proceedings of SPIE (pp. 662-667).

Berk, A., Bernstein, L. S., \& Robertson, D. C. (1989). MODTRAN: A moderate resolution model for LOWTRAN7. AFGL-TR-89-0122. MA: Hanscom Air Force Base.

Boden, T. A., Marland, G., \& Andres, R. J. (2011). Global, regional, and national fossil-fuel $\mathrm{CO}_{2}$ emissions. Oak Ridge, Tenn., USA: Carbon Dioxide Information Analysis Center, Oak Ridge National Laboratory, U.S. Department of Energy.

Boesch, H., Baker, D., Connor, B., Crisp, D., \& Miller, C. (2011). Global characterization of $\mathrm{CO}_{2}$ column retrievals from shortwave-infrared satellite observations of the orbiting carbon observatory-2 mission. Remote Sensing, 3, 270-304.
Bovensmann, H., Buchwitz, M., Burrows, J. P., Reuter, M., Krings, T., Gerilowski, K., et al. (2010). A remote sensing technique for global monitoring of power plant $\mathrm{CO}_{2}$ emissions from space and related applications. Atmospheric Measurement Techniques, 3 781-811.

Bradley, E. S., Leifer, I., Roberts, D. A., Dennison, P. E., \& Washburn, L. (2011). Detection of marine methane emissions with AVIRIS band ratios. Geophysical Research Letters, 38, L10702.

Briggs, G. A. (1973). Diffusion estimation for small emissions. : Air Resources Atmospheric Turbulence and Diffusion Laboratory, National Oceanic and Atmospheric Administration.

Briggs, G. A. (1984). Plume rise and buoyancy effects. In D. Randerson (Ed.), Atmospheric science and power production (pp. 327-366). : U.S. Department of Energy.

Butz, A., Hasekamp, O. P., Frankenberg, C., \& Aben, I. (2009). Retrievals of atmospheric $\mathrm{CO}_{2}$ from simulated space-borne measurements of backscattered near-infrared sunlight: Accounting for aerosol effects. Applied Optics, 48, 3322-3336.

Chevallier, F., Maksyutov, S., Bousquet, P., Breon, F. M., Saito, R., Yoshida, Y., et al. (2009) On the accuracy of the $\mathrm{CO}_{2}$ surface fluxes to be estimated from the GOSAT observations. Geophysical Research Letters, 36.

Ciais, P., Paris, J.D., Marland, G., Peylin, P., Piao, S. L., Levin, I., et al. (2010). The European carbon balance. Part 1: Fossil fuel emissions. Global Change Biology, 16, 1395-1408.

Crevoisier, C., Chedin, A., Matsueda, H., Machida, T., Armante, R., \& Scott, N. A. (2009). First year of upper tropospheric integrated content of $\mathrm{CO}_{2}$ from IASI hyperspectral infrared observations. Atmospheric Chemistry and Physics, 9, 4797-4810.

Crisp, D., Atlas, R. M., Breon, F. M., Brown, L. R., Burrows, J. P., Ciais, P., et al. (2004). The orbiting carbon observatory (OCO) mission. Trace Constituents in the Troposphere and Lower Stratosphere, 34, 700-709.

Dennison, P. E. (2006). Fire detection in imaging spectrometer data using atmospheric carbon dioxide absorption. International Journal of Remote Sensing, 27, 3049-3055.

Dennison, P. E., \& Roberts, D. A. (2009). Daytime fire detection using airborne hyperspectral data. Remote Sensing of Environment, 113, 1646-1657.

Dennison, P. E., Roberts, D. A., Thorgusen, S. R., Regelbrugge, J. C., Weise, D., \& Lee, C. (2003). Modeling seasonal changes in live fuel moisture and equivalent water thickness using a cumulative water balance index. Remote Sensing of Environment, 88, 442-452.

Dennison, P. E., Thorpe, A. K., Roberts, D. A., \& Green, R. O. (2013). Modeling sensitivity of imaging spectrometer data to carbon dioxide and methane plumes. 5th Workshop on hyperspectral image and signal processing: Evolution in remote sensing, Gainesville Florida.

Deschamps, A., Marion, R., Briottet, X., Foucher, P. Y., \& Lavigne, C. (2011). Simultaneous $\mathrm{CO}_{2}$ and aerosol retrieval in a vegetation fire plume using AVIRIS hyperspectral data. Hyperspectral image and signal processing: Evolution in remote sensing (WHISPERS), 2011 3rd workshop. Lisbon, Portugal.

EPA (2011). Inventory of U.S. Greenhouse gas emissions and sinks: 1990-2009. Washington, D.C.: United States Environmental Protection Agency (EPA).

EPA (2012). Inventory of U.S. Greenhouse gas emissions and sinks: 1990-2010. Washington, D.C.: United States Environmental Protection Agency (EPA).

ESI (1971). Exhaust gases from combustion and industrial process: A report prepared for the Division of Compliance, Bureau of Stationary Source Pollution Control, Office of Air Programs, U.S. Environmental Protection Agency, Technical Center. Washington, D.C.: Engineering-Science Inc.

Forster, P., Ramaswamy, V., Artaxo, P., Berntsen, T., Betts, R., Fahey, D. W., et al. (2007). Changes in atmospheric constituents and in radiative forcing. In S. Solomon, D. Qin, M. Manning, Z. Chen, M. Marquis, K. B. Averyt, M. Tignor, \& H. L. Miller (Eds.), Climate Change 2007: The physical science basis: Contribution of Working Group I to the Fourth Assessment Report of the Intergovernmental Panel on Climate Change (pp. 129-234). Cambridge: Cambridge University Press.

Funk, C. C., Theiler, J., Roberts, D. A., \& Borel, C. C. (2001). Clustering to improve matched filter detection of weak gas plumes in hyperspectral thermal imagery. IEEE Transactions on Geoscience and Remote Sensing, 39, 1410-1420.

Gao, B. C., \& Goetz, A. F. H. (1990). Column atmospheric water vapor and vegetation liquid water retrievals from airborne imaging spectrometer data. Journal of Geophysical Research, 95, 3549-3564.

Gerilowski, K., Tretner, A., Krings, T., Buchwitz, M., Bertagnolio, P. P., Belemezov, F., et al. (2011). MAMAP-A new spectrometer system for column-averaged methane and carbon dioxide observations from aircraft: Instrument description and performance analysis. Atmospheric Measurement Techniques, 4, 215-243.

Green, R. O., Conel, E. J., \& Roberts, D. A. (1993). Estimation of aerosol optical depth, pressure elevation, water vapor, and calculation of apparent surface reflectance from radiance measured by the airborne visible/infrared imaging spectrometer (AVIRIS) using a radiative transfer code. Proc. SPIE, 1937, Imaging Spectrometry of the Terrestrial Environment, 2.

Green, R., Eastwood, M. L., \& Williams, O. (1998). Imaging spectroscopy and the airborne visible/infrared imaging spectrometer (AVIRIS). Remote Sensing of Environment, 65, 227-248.

Gregg, J. S., Andres, R. J., \& Marland, G. (2008). China: emissions pattern of the world leader in $\mathrm{CO}_{2}$ emissions from fossil fuel consumptions and cement production. Geophysical Research Letters, 35, L08806.

Guerlet, S., Butz, A., Schepers, D., Basu, S., Hasekamp, O. P., Kuze, A., et al. (2013). Impact of aerosol and thin cirrus on retrieving and validating XCO2 from GOSAT shortwave infrared measurements. Journal of Geophysical Research-Atmospheres, 118, 1-19.

Hanna, S., Briggs, G. A., \& Hosker, R. P. (1982). Handbook on atmospheric diffusion. Technical Information Center, US Department of Energy (DOE/TIC-11223).

Herold, M., Roberts, D. A., Gardner, M. E., \& Dennison, P. E. (2004). Spectrometry for urban area remote sensing-Development and analysis of a spectral library from 350 to $2400 \mathrm{~nm}$. Remote Sensing of Environment, 91, 304-319.

Houweling, S., Hartmann, W., Aben, I., Schrijver, H., Skidmore, J., Roelofs, G. J., et al (2005). Evidence of systematic errors in SCIAMACHY-observed $\mathrm{CO}_{2}$ due to aerosols. Atmospheric Chemistry and Physics, 5, 3003-3013. 
IEA (2011). Key World Energy Statistics. : International Energy Agency (IEA) (http://www. iea.org/textbase/nppdf/free/2011/key_world_energy_stats.pdf).

Jiang, X., Chahine, M. T., Olsen, E. T., Chen, L. L., \& Yung, Y. L. (2010). Interannual variability of mid-tropospheric $\mathrm{CO}_{2}$ from atmospheric infrared sounder. Geophysical Research Letters, 37.

Kulawik, S. S., Jones, D. B.A., Nassar, R., Irion, F. W., Worden, J. R., Bowman, K. W., et al. (2010). Characterization of tropospheric emission spectrometer (TES) $\mathrm{CO}_{2}$ for carbon cycle science. Atmospheric Chemistry and Physics, 10, 5601-5623.

Leifer, I., Roberts, D., Margolis, J., \& Kinnaman, F. (2006). In situ sensing of methane emissions from natural marine hydrocarbon seeps: A potential remote sensing technology. Earth and Planetary Science Letters, 245, 509-522.

Marion, R., Michel, W., \& Faye, C. (2004). Measuring trace gases in plumes from hyperspectral remotely sensed data. IEEE Transactions on Geoscience and Remote Sensing, 42, 854-864.

Matheson, D. S., \& Dennison, P. E. (2012). Evaluating the effects of spatial resolution on hyperspectral fire detection and temperature retrieval. Remote Sensing of Environment $124,780-792$.

Miller, C. E., \& Dinardo, S. J. (2012). CARVE: The carbon in arctic reservoirs vulnerability experiment. Aerospace conference, 2012 IEEE

Montes, M. J. (2004). AVIRIS artifacts appearing in low-light imagery. Proceedings of the 13th Airborne Earth Science Workshop, Pasadena, California.

NOAA (2012). GMD measurement locations. : National Oceanic \& Atmospheric Administration (NOAA), Earth System Research Laboratory, Global Monitoring Division (http://www. esrl.noaa.gov/gmd/ccgg/trends/global.html).

NRC (2010). Verifying greenhouse gas emissions: Methods to support International Climate Agreements. Committee on Methods for Estimating Greenhouse Gas Emissions; National Research Council. Washington, D.C.: The National Academies Press.

Ogunjemiyo, S., Roberts, D. A., Keightley, K., Ustin, S. L., Hinckley, T., \& Lamb, B. (2002) Evaluating the relationship between AVIRIS water vapor and poplar plantation evapotranspiration. Journal of Geophysical Research, 107(D23), 4719.

Roberts, D. A., Bradley, E. S., Cheung, R., Leifer, I., Dennison, P. E., \& Margolis, J. S. (2010). Mapping methane emissions from a marine geological seep source using imaging spectrometry. Remote Sensing of Environment, 114, 592-606.
Roberts, D. A Dennison, P. E Morais, M. E Gardner, M. E Regelbrugge, J. \& Ustin, S. L (1999). Mapping wildfire fuels using imaging spectrometry along the wildland urban interface. Proc. 1999 Joint Fire Science Conference and Workshop, June 17-19, Boise, ID (pp. 213-223).

Roberts, D. A., Green, R. O., \& Adams, J. B. (1997). Temporal and spatial patterns in vegetation and atmospheric properties from AVIRIS. Remote Sensing of Environment, 62, 223-240.

Saitoh, N., Imasu, R, Ota, Y. \& Niwa, Y. (2009). $\mathrm{CO}_{2}$ retrieval algorithm for the thermal infrared spectra of the Greenhouse Gases Observing Satellite: Potential of retrieving $\mathrm{CO}_{2}$ vertical profile from high-resolution FTS sensor. Journal of Geophysical ResearchAtmospheres, 114.

Schneising, O., Bergamaschi, P., Bovensmann, H., Buchwitz, M., Burrows, J. P., Deutscher, N. M., et al. (2012). Atmospheric greenhouse gases retrieved from SCIAMACHY: Comparison to ground-based FTS measurements and model results. Atmospheric Chemistry and Physics, 12, 1527-1540.

Schneising, O., Buchwitz, M., Burrows, J. P., Bovensmann, H., Reuter, M., Notholt, J., et al. (2008). Three years of greenhouse gas column-averaged dry air mole fractions retrieved from satellite-Part 1: Carbon dioxide. Atmospheric Chemistry and Physics, 8, 3827-3853.

Shettle, E. P., \& Fenn, R. W. (1979). Models for the aerosols of the lower atmosphere and the effects of humidity variations on their optical properties. Air Force Geophysics Laboratory Technical Report AFG-TR-79-0214.

Spinetti, C., Carrere, V., Buongiorno, M. F., Sutton, A. J., \& Elias, T. (2008). Carbon dioxide of Pu'u'O'o volcanic plume at Kilauea retrieved by AVIRIS hyperspectral data. Remote Sensing of Environment, 112, 3192-3199.

Thorpe, A. K., Roberts, D. A., Bradley, E. S., Funk, C. C., Dennison, P. E., \& Leifer, I. (2013). High resolution mapping of methane emissions from marine and terrestrial sources using a Cluster-Tuned Matched Filter technique and imaging spectrometry. Remote Sensing of Environment, 134, 305-318.

Velazco, V. A., Buchwitz, M., Bovensmann, H., Reuter, M., Schneising, O., Heymann, J., et al. (2011). Towards space based verification of $\mathrm{CO}_{2}$ emissions from strong localized sources: Fossil fuel power plant emissions as seen by a CarbonSat constellation. Atmospheric Measurement Techniques, 4, 2809-2822. 